\title{
Exploring the personal and professional factors associated with student evaluations of tenure-track faculty
}

\author{
Dakota Murray $^{1}$, Clara Boothby ${ }^{1}$, Huimeng Zhao ${ }^{2}$, Vanessa Minik ${ }^{1}$, Nicolas Bérubé ${ }^{3}$, \\ Vincent Larivière ${ }^{3}$, Cassidy R. Sugimoto ${ }^{1^{*}}$ \\ 1 School of Informatics, Computing, and Engineering, Indiana University, Bloomington, \\ Indiana, U.S.A. \\ 2 Department of Sociology, University of Chicago, Chicago, Illinois, U.S.A. \\ 3 École de bibliothéconomie et des sciences de l'information, Université de Montréal, \\ Montreal, Quebec, Canada \\ * sugimoto@indiana.edu
}

\begin{abstract}
Tenure-track faculty members in the United States are evaluated on their performance in both research and teaching. In spite of accusations of bias and invalidity, student evaluations of teaching have dominated teaching evaluation at U.S. universities.

However, studies on the topic have tended to be limited to particular institutional and disciplinary contexts. Moreover, in spite of the idealistic assumption that research and teaching are mutually beneficial, few studies have examined the link between research performance and student evaluations of teaching. In this study, we conduct a large scale exploratory analysis of the factors associated with student evaluations of teachers, controlling for heterogeneous institutional and disciplinary contexts. We source public student evaluations of teaching from RateMyProfessor.com and information regarding career and contemporary research performance indicators from the company Academic Analytics. The factors most associated with higher student ratings were the attractiveness of the faculty and the student's interest in the class; the factors most associated with lower student ratings were course difficulty and whether student comments mentioned an accent or a teaching assistant. Moreover, faculty tended to be rated more highly when they were young, male, White, in the Humanities, and held a rank of full professor. We observed little to no evidence of any relationship, positive or negative, between student evaluations of teaching and research performance. These results shed light on what factors relate to student evaluations of teaching across diverse contexts and contribute to the continuing discussion teaching evaluation and faculty assessment.
\end{abstract}




\section{Introduction}

Performance indicators have come to dominate faculty evaluations of teaching and research at universities in the United States, raising concerns over their consequences [1]. One of the most prominent indicators for teaching are student evaluations of teaching (SETs), in which students anonymously score and comment on their course instructors for the purpose of evaluation and improvement. However, SETs alone are not sufficient for evaluation of tenure and tenure-track faculty for whom teaching constitutes only a portion of their professional responsibilities. Contemporary research universities are built on the premise that faculty balance research, service to the academic community, and teaching (see Boyer's model of scholarship [2]). Holistic faculty evaluation requires assessments along each of these dimensions and the faculty's ability to balance their commitments. However, quantitative studies of SETs typically have not examined teaching ratings in relation to faculty performance in other professional activities. Studies of SETs are also limited by the difficulty of aggregating data across institutional contexts, which has resulted in a poor understanding of the extent to which SETs depend on institutional and disciplinary factors. There is a need for a large-scale analysis of SETs to provide a more complete understanding of the extent to which these evaluations relate to personal or professional characteristics of teachers, institutional context, and research performance.

Questions of bias in SETs have prompted intense scrutiny and numerous studies on their validity. For example, past research on traditional SETs has identified biases based on gender [3], race [6, 9], attractiveness [10], and age 7, 11, 12. Many have also criticized traditional SETs as invalid measures of teaching quality and student learning [3, 7, 12,17 and warned university administrators against using them for hiring and promotion decisions $[18$. In light of these issues, there have been intensifying claims that SETs harm both students and faculty 19 and public calls to stop relying on them for evaluating teaching 20,21. In spite of this controversy, SETs have remained one of the most common metrics of teaching performance across a variety of U.S.

universities [22]. Given their continued use for hiring and promotion, there remains a need to study the factors contributing to outcomes on SETs.

The research-teaching nexus refers to the relationship between time spent doing research, and time spent teaching. The Humboldtian ideal of a university is built on the premise that these tasks are mutually beneficial [23, and many have followed this tradition, positing a strong relationship between research and teaching 2427 . However, there is a lack of consensus surrounding the presence, extent, and nature of the nexus. While some studies have found evidence of positive research-teaching nexus - a mutually-beneficial relationship 28 30, other studies have instead observed a negative research-teaching nexus, suggesting that faculty incentive structures encourage research at the expense of teaching quality [31-33. Conflicting with both the positive and negative nexus hypotheses, a landmark meta-analysis instead suggested a neutral research-teaching nexus, observing no evidence of a relationship between research and teaching [34]. Taken together, these studies offer no clear understanding of the research-teaching nexus; moreover, these studies have tended to be small and limited to particular institutional contexts. There remains a pressing need to understand the research-teaching nexus at scale and across institutional contexts.

In this study, we conduct a large-scale exploratory investigation of the extent to which demographic characteristics and research performance relate to SETs for tenured and tenure-track faculty in the United States. We leverage public teaching evaluations from RateMyProfessor.com, a public data source of public SETs which, despite criticism 35, 36], has been found to correlate with traditional evaluations $37 \sqrt[40]{40}$. We match these teaching evaluations with records from Academic Analytics, a research analytics company which provided us with a list of active tenured and tenure-track 
faculty in the United States, along with indicators of their number of publications, citations, grants, and professional awards. In performing this analysis, we hope to gain a more complete understanding of how individual, classroom, university characteristics, and research performance correlate with university faculty's teaching evaluations. We also aim to shed light on the research-teaching nexus, the relationship between research and teaching.

\section{Data and methods}

\section{Academic Analytics}

Academic Analytics is a U.S. based company that sells access to their proprietary dataset of individual-level bibliometric indicators for use by university administrators in the United States and the United Kingdom to assess their departments. This data is derived from a mix of direct cooperation with research institutions and collection from publicly available sources such as institutional websites, CrossRef, and Federal agencies. We maintain a contract with Academic Analytics, through which we are granted a copy of their 2017 data release (AA2017).

The version of AA2017 used in this study contained demographic and bibliometric data for 165,666 tenure and tenure-track faculty at 399 universities and research institutions in the United States. AA2017 contains full names, departmental and institutional affiliations, year of doctoral attainment, and disciplinary classification. The dataset also included bibliometric indicators of recent scholarly performance: indexed publications produced in the previous five years; citations to those publications; grants held in the previous five years; lifetime professional awards won; and books published within the past ten years. Details and definitions of the relevant variables from AA2017 can be found in S1 Table.

\section{RateMyProfessor.com}

RateMyProfessor.com is a website offering students at institutions of higher education the opportunity to review their teachers and to read reviews by other students. Founded in 1999, the most recent version of RateMyProfessor.com allows students to anonymously review teachers along dimensions of overall quality, level of difficulty, and until recently, "hotness" - a binary rating implicitly associated with physical attractiveness (see S1 Text for discussion of rating types removed from the website). Ratings on RateMyProfessor.com have been found to correlate with traditional student-evaluations of teachers (see S2 Text). Students are also encouraged to post comments to elaborate on their experience, and to select from a list of pre-defined "tags" that describe the common characteristics of the teacher and the course. Teachers, courses, and schools are all added to RateMyProfessor.com by users, and so the presence of any individual depends on the effort of students. Although the website has passed through many iterations, these core features have remained roughly consistent over time. RateMyProfessor.com remains one of the only and most popular large-scale, publicly available source of students' evaluations of teachers, boasting "... more than 19 million ratings, 1.7 million professors and over 7,500 schools" 41]. We collected these data in January of 2018. Details and definitions of relevant variables from this data can be found in $\$ 2$ Table and $\mathrm{S3}$ Table

\section{Disciplinary aggregation}

The AA2017 dataset used a hierarchical three-tiered disciplinary taxonomy, with the most granular tier consisting of 171 distinct classifications that were applied based on 
each individual's departmental affiliation. When an individual held multiple affiliations or when a program was classified as more than one discipline, Academic Analytics duplicated their entire record, changing only their disciplinary classification. Thus, while there were 165,666 unique tenure and tenure track faculty represented in in AA2017, 42,500 of these individuals had at least one duplicate record, which resulted in 225,877 total records.

To streamline the large variety of AA disciplinary classifications, we manually mapped each of the AA2017 171 detailed classifications to one of the five NSF classifications of research discipline: "Natural Sciences", "Medical Sciences", "Social Sciences", "Humanities", and "Engineering". After we applied these broad disciplinary classifications, 16,254 individuals had duplicate records with distinct NSF classifications, compared to the 42,500 with distinct Academic Analytics classifications.

\section{Processing research indicators}

We added a new research indicator for each individual, Publication Count, which we defined as the sum of their indexed conference proceedings, book publications, and article publications; this combined indicator simplifies analysis, and captures the range of publications types that have distinct disciplinary distributions [42] (see distributions in S1 Fig). The final indicators included the number of recent publications (5 years for articles and conferences, 10 for books), the number of citations to those recent publications, the number of grant dollars currently held, and the number of lifetime professional awards held by the individual. We field-normalized each AA2017 research indicator by the mean across the 171 granular disciplinary categories. This was performed for each record, normalizing by the mean of that record's associated granular discipline. For example, if an individual published ten times within the past five years, and had two records, one for discipline A, with a field-mean of 5 publications, and one for discipline B with field-mean of 15 publications, then that individual's records would have field-normalized scores of 2.0 and 0.667 , respectively.

We also created discretized versions of each continuous field-normalized indicator of research performance. We binned each research indicator into an ordered factor containing a value of "None", "Moderate", or "High". A classification of "None" meant that a count of zero is reported for that indicator. "Moderate" meant that the reported count is between the 1 st and $90^{\text {th }}$ percentile (inclusive) for that research indicator,

calculated on the population of individuals who have a count greater than one. "High" meant that the reported count was above the $90^{\text {th }}$ percentile of those with a count of at least one for that indicator. We performed this discretization because each field-normalized indicator is strongly zero-inflated and right-skewed (see the log-log distribution of indicators in S1 Fig); these categories mitigated the impact of outliers and allowed for a clearer comparison between those with and without recent research activity.

\section{Record matching}

After the above pre-processing steps, we attempting to match records between the AA2017 and RMP2018 datasets. For each individual in AA2017, we attempted to find a likely match within RMP2018. After extensive experimentation and parameter tuning we settled on using Jaro-Winkler string distance $43 \sqrt{45}$ as the measure of distance between records. This measure offers flexibility to handle minor variation in instructor and department names. Distance between two strings is based on the number of character matches that occur in similar indexes in both strings, and includes a penalty factor that penalizes strings that have a mismatch within the first few characters. Given 
that this measure prioritizes matches early in the string, we format match strings for records in AA2017 and RMP2018 as follows,

\section{[LAST NAME] [MIDDLE INITIAL] [FIRST NAME] [PROGRAM AFFILIATION]}

where [PROGRAM AFFILIATION] is the "Program Name" variable in AA2017 and the "Department" variable in RMP (see S2 Table and S3 Table for descriptions of these variables). Using this format, Jaro-Winkler distance will tend to enforce strict similarity between last names while allowing for some increased variation in first names and department names. This is especially useful for faculty who use informal nicknames while teaching; for example, an individual in AA2017 with the match string "Smith Robert Applied Mathematics" results in a relatively high similarity score with an individual from RMP2018 with the name "Smith Bob Applied Mathematics".

We calculated pairwise Jaro-Winkler string distances between the match strings for each individual in AA2017 and each profile from RMP2018. If the largest similarity metric between a record from AA2017 and any profile on RMP was lower than 0.1, then we excluded that individual from the final dataset. If at least one RMP profile has a similarity score above the threshold, then the most similar profile was selected as a match. This process resulted in 47,509 matches between individuals in AA2017 and RMP, representing 34.5 percent of AA2017 records, and 3.0 percent of all RMP2018 records; this small population of matched RMP2018 records is expected because RateMyProfessor.com included non-tenured/non-tenure track faculty, faculty who are no longer active, and faculty from countries not represented in our version of AA2017.

A discussion of the representativeness and potential biases in our matching process can be found in S3 Text for AA2017 and S4 Text for RMP2018.

\section{Gender assignment}

We assigned a gender to each record in the matched dataset by comparing the number of masculine and feminine pronouns that appeared in text reviews left on faculty's profiles on RateMyProfessor.com. If the reviews of a profile contained more of one type of gendered pronouns than the square of the other, then we assigned their gender using the gender of the majority pronoun. For example, if one profile's reviews contained a total of ten masculine pronouns (e.g.: "he", "him", "himself"), but only three feminine pronouns (e.g.: "she", "her", "herself"), that profile would be assigned a gender of male $\left(10>3^{2}\right)$; however if a profile contained four masculine and three feminine pronouns, then no gender was assigned $\left(3^{3}>4\right)$. Using this method, we assigned a gender of male or female to 99.7 percent of tenure and tenure-track professors in the final matched dataset.

\section{Race assignment}

We infer a race for each individual in our dataset from their surname. We retrieved the dataset of surnames from the US Census, which contains, for each surname, the percentage of individuals having that name that are White, Black, Asian, Hispanic, Native American or Pacific Islander, and two or more races, as determined by the census. We adopt a conservative and course-grained approach to inferring race from these information; An individual in our dataset is assigned as Likely White when at least 70 percent of those having the same surname are White. Otherwise, an individual is assigned Likely Non-White. When an individual's surname does not appear in the Census dataset, then they are assigned a race of Unknown. 


\section{Final dataset}

For those individuals in AA2017 who had duplicate records due to multiple affiliations, $\quad{ }_{193}$ we selected one record at random and excluded others. We also removed records that were not assigned a value for their Scientific Age in AA2017 for which no gender could be assigned, and which had fewer than three reviews on RateMyProfessor.com. We excluded faculty who had fewer than five reviews in order to mitigate noise. The final matched dataset contained 18,946 records. Finally, we enriched these data with university characteristics from the 2018 Carnegie Classification of Higher Education Institutions. Analysis was conducted on a set of relevant variables extracted from the matched and enriched dataset. Descriptions of these final variables, identified following an extensive literature review of factors relevant to teaching performance, can be found in Table 1. These variables reflect a range of individual, classroom, university, and professional characteristics of the faculty and their teaching. These data, and the code for processing it, can be found at https://github.com/murrayds/aa_rmp. 


\section{Results}

We fit a linear regression model with the overall teaching quality as the response, and all other variables from Table 1 as predictors. The resulting model had a $R^{2}$ of 0.514 . Fig. 1. A visualizes the estimates of this regression (also shown in S4 Table). Because this is an exploratory analysis, we do not report p-values or significance levels for parameter estimates.

Several personal characteristics of faculty were associated with ratings of overall teaching quality in RMP2018. Presence of the "chili pepper" in RMP2018, which implies attractiveness, was associated with 0.41 point higher overall teaching quality $(\beta=0.42,95 \% \mathrm{CI}=[0.39,0.44])$; this was the largest positive estimate from the model. Compared to female faculty, male faculty were associated with 0.11 points greater overall teaching quality $(\beta=0.11,95 \% \mathrm{CI}=[0.08,0.13])$. Faculty having a commonly White surname were associated with 0.118 points greater overall teaching quality $(\beta=0.12,95 \% \mathrm{CI}=[0.10,0.14]$, whereas those with unknown race were associated with slightly higher ratings $(\beta=0.05,95 \% \mathrm{CI}=[0.019,0.074])$. Faculty who were mentioned as having an accent in a comment left on their RMP2018 profile were associated with 0.17 point lower ratings of overall quality than those for whom an accent was not mentioned $(\beta=-0.17,95 \% \mathrm{CI}=[-0.20,-0.14])$. Scientific age was negatively correlated with overall teaching quality such that each additional decade was associated with 0.13 point lower rating $(\beta=-0.13,95 \% \mathrm{CI}=[-0.15,-0.12])$. Professional rank had some association with ratings of overall teaching quality. Compared to assistant professors, full professors were associated with 0.14 point higher ratings of overall teaching quality $(\beta=0.14,95 \% \mathrm{CI}=[0.1,0.17])$; associate professors were associated with only 0.05 point higher ratings $(\beta=0.047,95 \% \mathrm{CI}=[0.017,0.076])$. Personal characteristics may also interact; for example, we observe evidence that White male faculty are higher than their Non-White, female counterparts $(\beta=0.051,95 \% \mathrm{CI}=[0.002,0.10])$, among other weaker interaction effects (S6 Table).

Characteristics of the class itself were also associated with ratings of overall teaching quality. The rated difficulty of the course was largest negative estimate from the model; each additional point of difficulty was associated with 0.39 lower points of overall teaching quality $(\beta=-0.39,95 \% \mathrm{CI}=[-0.40,-0.38])$. The student interest ratings of a faculty was the second largest positive estimate; each additional point in interest was associated with 0.33 points higher overall teaching quality

$(\beta=0.33,95 \% \mathrm{CI}=[0.32,0.34])$. Faculty for whom a comment on RMP2018 mentioned a teaching assistant were associated with 0.18 point lower ratings of overall quality $(\beta=-0.18,95 \% \mathrm{CI}=[-0.22,-0.15])$.

Associations between university characteristics and ratings of overall teaching quality were found to be weaker than for individual and class characteristics. Compared to all others, R1 universities - doctoral universities with very high research activity (as identified by the Carnegie Classification of Higher Education Institutions) - were associated with 0.03 point lower ratings of overall quality

$(\beta=0.03,95 \% \mathrm{CI}=[-0.05,-0.01]$. Compared to those in private universities, faculty affiliated with public universities were associated with 0.08 point lower teaching evaluations $(\beta=-0.08,95 \% \mathrm{CI}=[-0.11,-0.06])$.

There were notable differences in ratings of overall teaching quality between disciplines. All other disciplines were rated as having higher overall quality than Engineering, the reference level; Engineering was chosen as the reference because it had the lowest ratings of overall teaching quality. Compared to Engineering, faculty in the Humanities were associated with 0.18 point higher overall quality ratings $(\beta=0.18,95 \% \mathrm{CI}=[0.14,0.23])$. After the Humanities, faculty in Medical Science were associated with 0.11 points higher ratings than those in Engineering $(\beta=0.11,95 \% \mathrm{CI}=[0.056,0.153])$, followed by faculty in the Natural Sciences 
Table 1. Description of final variables. Extracted from RateMyProfessor.com (RMP2018), the 2017 version of Academic Analytics (AA2017), and the Carnegie Classification of Higher Education Institutions (Carnegie) for matched profiles

\begin{tabular}{lll}
\hline Variable & Source & Description \\
\hline Overall Quality & RMP2018 & The average of all 1-5 point reviews of overall quality left for a professor on \\
& $\begin{array}{l}\text { RateMyProfessor.com between } 2012 \text { and 2017. Ratings are aggregated across } \\
\text { all courses }\end{array}$
\end{tabular}

Difficulty

RMP2018

Interest

RMP2018

Number of reviews

Mentions Accent

Mentions TA

Has Chili Pepper

Gender

Inferred Race

Discretized: Citedness; Output; Awards Won; Grants Held

Scientific Age

Discipline

Rank

Uni. Type

Uni. Control
AA2017

AA2017

AA2017

Carnegie

RMP2018

RMP2018

RMP2018

RMP2018

Mixed

Mixed

AA2017

Carnegie
The average of all 1-5 point reviews of difficulty left for a professor on RateMyProfessor.com between 2012 and 2017. Ratings are aggregated across all courses

The average of all 1-5 point reviews of student interest left for a professor on RateMyProfessor.com between 2012 and 2017. Original levels marked by an order set of five qualitative levels. These levels were mapped to values between 1 and 5 to accommodate numeric calculations. Ratings are aggregated across all courses

The number of reviews left for the professor between 2012 and 2017. We use this as a control variable

True if the word "accent" appears at least once in the text of reviews for an individual

True if the word "TA" or "Teaching Assistant" appears at least once in the text of reviews for an individual

True if the individual is given a "chili pepper" symbol, implicitly a rating of physical attractiveness

Gender assigned to each individual of the dataset. Assigned using pronouns included in comments from RMP2018 data

Inferred race assigned to each individual in the dataset based on their family name.

Four variables: Citedness, scholarly output, awards won, and grants held. Each variable represents a count of recent field-normalized research items, categorized into three discrete groups. More detail on how each of these research items is counted by AA is included in supplementary information. Assigned category of "None" if no research item. Assigned "Moderate" if not None, and if between the 1st and 90th percentile (inclusive) of those with at least one of that research item; assigned "High" if greater than $90^{\text {th }}$ percentile

Number of years, in decades, since the individual obtained their terminal degree

High-level discipline of individual. One of Natural Sciences, Medical Sciences, Social Sciences, Engineering, or Humanities. In case a user was assigned to multiple disciplines, one was randomly selected

The professional rank of the individual, coded as Associate, Assistant, or Full

The classification of the research activity of the institution: R1 or Not R1

The classification of the "control" of the institution that the individual is affiliated with: Public or Private 


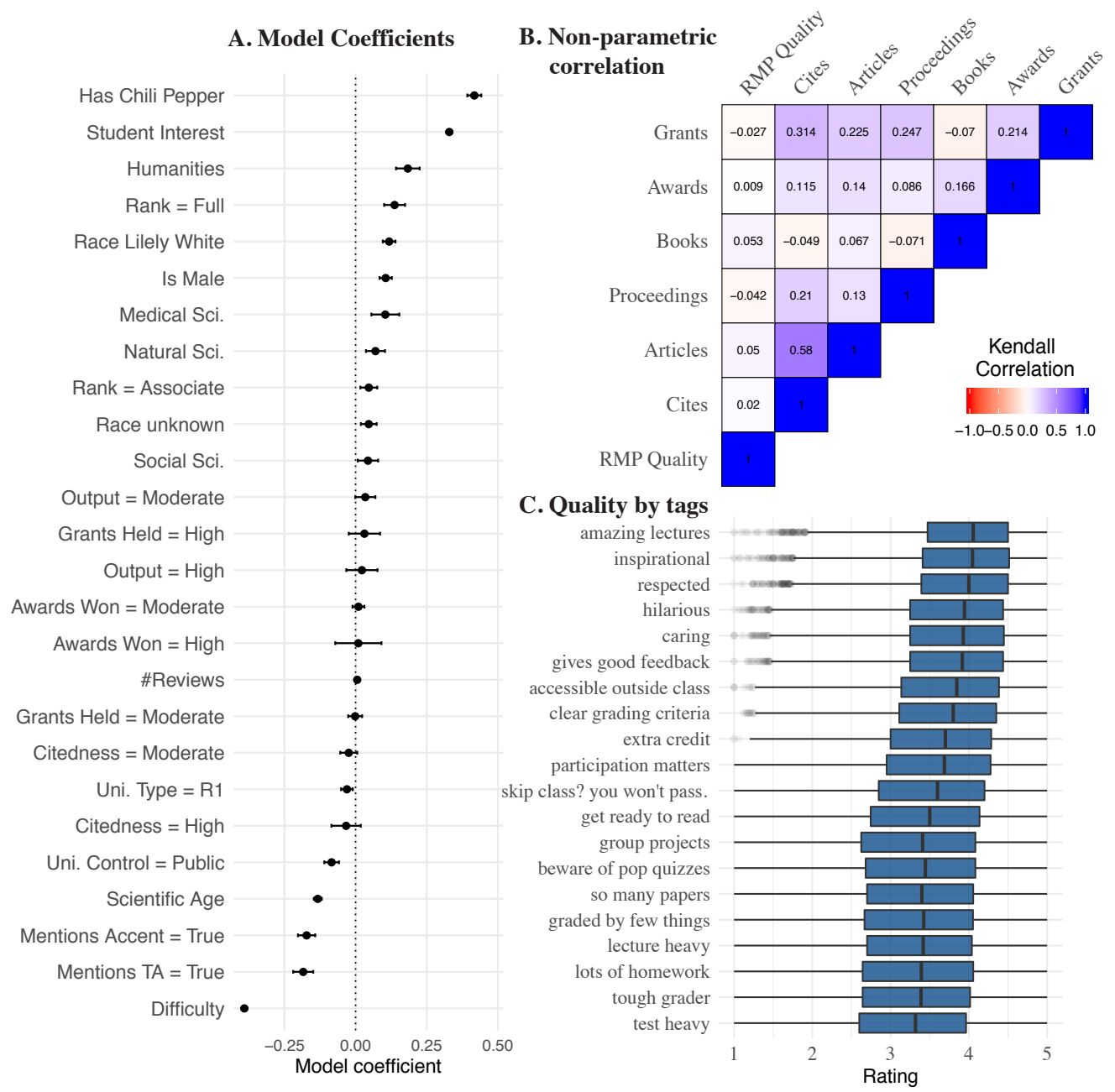

Fig 1. Individual, Classroom, University, and Research characteristics associated with overall teaching quality. A. Estimates of linear regression model using the overall teaching quality (continuous, 1-5) as the response and all variables from table 1 as the predictor variables. The $\mathrm{x}$-axis corresponds to the estimate for each covariate, which are listed along the y-axis. For binary variables, "false" is always used as the reference level. For Gender, "female" is used as the reference. For race,

"Non-White" is used as the reference. For "Rank", "Assistant" is used as the reference. For Discipline, "Engineering" is set as the reference. For Uni. Control, "Private" is used as the reference. For Uni. Type, "Not R1" is used as the reference. For all research indicators, "Low" is used as the reference. Error bars surrounding each point correspond to the $95^{\text {th }}$ percentile confidence intervals. Results are also shown in S4 Table. B. The non-parametric Kendall Rank Tau between research indicators and overall teaching quality. Values map to the correlation between 1 (correlated) and -1 (inversely correlated). Raw values for this test can be found in S5 Table C. The distribution of overall teaching quality ratings for faculty possessing each of the pre-defined "tags" listed on their RateMyProfessor.com profile.

$(\beta=0.07,95 \% \mathrm{CI}=[0.037,0.10])$ and finally faculty in the Social Sciences $(\beta=0.044,95 \% \mathrm{CI}=[0.008,0.079])$. Distinct disciplinary contexts can also interact with other variables. While a complete cross-disciplinary analysis is out of the scope of the present study, we conduct a preliminary analysis of how gender interacts with 
discipline. We found that while male faculty get higher ratings, and Humanities and Natural Science faculty are rated more highly than those in Engineering, this total disparity fell when considering the Male/Humanities and Male/Natural Sciences combinations of factors S6 Table.

Research indicators were only weakly or trivially associated with ratings of overall research quality. During analysis, we designated three levels of field-normalized research productivity over the past 5 years: no publications, moderate (at least one publication, less than or equal to the $90^{\text {th }}$ percentile), and high (above the $90^{\text {th }}$ percentile); this was repeated for all research indicators. Compared to faculty with no publications in the past five years, faculty with moderate publication were associated with 0.034 point higher ratings $(\beta=0.034,95 \% \mathrm{CI}=[-0.001,0.069])$ - this was the only estimate for which confidence intervals only barely crossed zero. Those with a high level of publications were associated with 0.022 point higher ratings $(\beta=0.022,95 \% \mathrm{CI}=[-0.033,0.077])$. Faculty with a moderate and high level of citations were associated with 0.024 point $(\beta=-0.024,95 \% \mathrm{CI}=[-0.054,0.006])$ and 0.033 point $(\beta=-0.033,95 \% \mathrm{CI}=[-0.085,0.018])$ lower teaching evaluations, respectively. Faculty with a moderate amount of grants were associated with only 0.002 point lower ratings $(\beta=-0.002,95 \% \mathrm{CI}=[-0.026,0.023])$ whereas those with a high amount of grants were associated with 0.031 point higher evaluations than those with no grants $(\beta=0.031,95 \% \mathrm{CI}=[-0.024,0.086])$. Finally, compared to those with no awards, those with a moderate amount of awards were associated with 0.01 point higher ratings of overall teaching quality $(\beta=0.01,95 \% \mathrm{CI}=[-0.011,0.031])$, and those with a high amount of awards were associated with a similar 0.01 point higher ratings $(\beta=0.01,95 \% \mathrm{CI}=[-0.071,0.091])$.

One limitation of this regression analysis was that research indicators, due to their zero-inflated and heavily-skewed distributions, were binned into one of three categorical values; this made them more amenable for analysis but could mask linear relationships. We sought to further assess the presence of the research-teaching nexus by repeating the regression analysis with continuous, rather than categorical variables for research performance indicators (results provided in S7 Table). However, this analysis provided no new evidence for the research-teaching nexus, presenting at most a trivial positive relationship between the field-normalized count of awards and the overall teaching quality $(\beta=0.008,95 \% \mathrm{CI}=[0.001,0.014])$. We computed an ANOVA test to compare the two approaches but observed no significant difference in the variance explained by the models $(\mathrm{p}=0.47)$. To mitigate the potential impact of multicollinearity, we also performed a regression model using the principal component of the continuous research indicators but still observed no evidence of a relationship between this variable and ratings of overall teaching quality. Additionally, we observed no strong evidence of multicollinearity from the adjusted generalized variance inflation factors of both the model with discrete indicators S8 Table, and the model with continuous indicators S9 Table. We also sought to assess the impact of omitted variable bias to see how the absence of research indicator could impact other estimates, but observe only trivial differences, with an ANOVA between the basic model and the model with discrete indicators (Fig. 1.A) showing no evidence of a difference $(p=0.49)$.

We also investigated the extent to which continuous research performance indicators were correlated with ratings of overall teaching quality using the non-parametric Kendall Rank Tau test (Fig. 11B). Non-parametric approaches may be better suited to understanding these zero inflated and skewed data. We calculated the correlations for all combinations of research indicators and separated total publication count into three variables corresponding to the count of articles, count of conference proceedings, and count of books indexed in AA2017 (these variables are described in S1 Table). However, we observed only trivial correlations between research indicators and ratings of overall 
teaching quality, the strongest having a value of 0.046 for the number of articles, followed by the number of books. For faculty with positive research indicators, we investigated the distribution of overall teaching quality by decile rank S2 Fig which revealed some evidence of a positive linear relationship between overall teaching quality and citations and publications. However, as these results did not bear out when partitioning by discipline (S3 Fig), when the linear trends all but disappeared; these small correlations may be confounded by disciplinary differences in publishing patterns and teaching quality. We note that the research indicators collected by Academic Analytics include only recent performance ( 5 years for publications and citations, 10 years for books) and do not represent faculty's full career, which may have proven more predictive of ratings of teaching quality.

Having observed the large estimates of individual and class characteristics from our regression analysis, we further investigated which characteristics of teaching were associated with the RateMyProfessor.com overall teaching quality rating. The website allows allows users posting a review to select from a 20 pre-defined tags that denote common characteristics of university faculty and classes. Fig. 1. C shows the distribution of overall quality scores for faculty having each of these tags. The tags associated with the highest ratings of overall teaching quality tend be personal characteristics of the instructor such as "amazing lectures", "inspirational", "respected", "hilarious", and "caring". The tags associated with the lowest ratings instead tend to refer to course characteristics, such as "graded by a few things", "lecture heavy", "lots of homework", "tough grader", and "lots of tests". The results from these tags confirm the relationship between difficulty and ratings observed in the regression model.

\section{Discussion}

Ideally, faculty evaluation would be an unbiased performance assessment, uninfluenced by gender, ethnicity, age, attractiveness, or other personal characteristics. However, empirical analyses of student evaluations of teaching (SETs) have demonstrated that they often fall short of this ideal $3-12$. Moreover as the ideal of the university posits a mutually beneficial research-teaching nexus, faculty evaluation should be holistic, considering performance across all professional responsibilities; however, assessments of the so-called research-teaching nexus have not produced a clear consensus of its presence, nature, or extent 28 34]. By constructing a large and heterogeneous dataset of tenure and tenure track faculty in the U.S., this exploratory study provides additional evidence of bias in SETs while also demonstrating little to no relationship between common indicators of teaching and research.

\section{Individual characteristics}

The strongest correlate with teaching evaluations was whether or not the faculty had a "chili pepper" rating on RateMyProfessor.com. The precise implication of the chili pepper is unclear, as it was never explicitly defined and so its meaning will vary between users. We conceive the "chili pepper" as a rating of the physical attractiveness of the instructor, following past research [46] and widespread cultural understandings [21]. Following controversy, this rating was removed in 2018 (see S1 Text) however it remained in use at the time of data collection. Our finding is consistent with studies of student evaluations in traditional evaluative settings [7, 47], studies of faculty's online self-presentation [48, and past studies of RateMyProfessor.com [10,46]. In unbiased evaluation, a faculty's physical attractiveness should not factor into the quality of their teaching or pedagogical skill. The relationship we observed could result from student's implicit bias favoring physically attractive faculty. It can also be interpreted as a "halo 
effect" [49], whereby student's positive impressions of one aspect of their professor (e.g.: their attractiveness) influences other aspects of their evaluation. Student's perceptions of physical attractiveness are also likely to differ with the perceived age, race, and gender of both the instructor and the students [50], resulting in different manifestations of this trend across different contexts. For example, younger faculty were more likely to be assigned a chili pepper, demonstrated by the negative trend between scientific age and probability of having a chili apparent in S4 Fig). While we control for some of these characteristics (e.g., age, gender), we cannot effectively control for others such as ethnicity and student demographics.

We observed a small trend such that male faculty tended to receive higher ratings (of 0.10 points) of overall teaching quality than female faculty. Past studies of traditional SETs have noted gender biases favoring men in experimental settings 8 and in large-scale observational studies [5]. Studies leveraging RateMyProfessor.com have observed gendered differences in language used to describe faculty [51] but findings of bias in evaluation scores have been mixed with reports of small or no significant gender bias depending on context 30,46]. We observed no evidence of gender difference in the distribution of overall ratings based on aggregate data (S5 Fig), but did observe a relationship when controlling for other variables such as scientific age, disciplines, and university context (Fig. 1.A); This discrepancy and the lack of consensus among studies suggests that gender bias in SETs is contingent on contextual factors of the university, discipline, and student body 3 .

Faculty with commonly-White family names tended to be rated more highly than others. This finding affirms past studies that identified racial bias in SETs such that persons of color, particularly black faculty, were rated lower than their White counterparts 6,962 . However, those with names absent from the U.S. Census data also tended to have higher ratings than Non-White faculty; we cannot speak to the precise demographics of these names, however these names were more common in fields such as Engineering (S6 Fig), which also tended to have the most Non-White associated family names S7 Fig). It is likely that the "unknown" category is therefore a mixture of White and Non-White faculty, the precise demographics of which require further investigation. We found evidence that race and gender interact, such that White Male faculty tended to be rated more highly than others, mirroring inter-sectional narratives. Related to race, faculty for whom an "accent" was mentioned in their evaluations tended to be rated lower than those for whom no accent was mentioned. RateMyProfessor.com and Academic Analysis offer no means of reliably inferring country of origin of faculty; here, we consider the mention of an accent as a proxy indicating non-native English speaker who may encounter bias and stereotyping in SETs. Whereas students often claim that instructor's accent is less important than their knowledge of the source material [53], accented faculty have been found receive lower evaluations, especially for comprehension [54]. On RateMyProfessor.com, a population of Asian-born professors (who may or may not have noticeable accents) were found to receive lower ratings than their U.S. born counterparts [55]. Non-White and foreign-born faculty face additional challenges when teaching such as stereotyping and prejudice. These approaches, while limited, demonstrate how biases can manifest in student's evaluations of faculty, which can hinder their career and produce additional inequality.

More senior faculty, in terms of the number of years since obtaining their Ph.D., tended to receive lower ratings; each additional decade of scientific age was associated with 0.13 point lower score. Most past research studying the relationship between age and SETs has studied actual age, a value which is likely correlated with the scientific age we study here. One study of data from RateMyProfessor.com found evidence that older instructors were rated lower, but that this effect disappears after controlling for other factors, such as their physical appearance and the difficulty of their courses [11. 
However, even after controlling for many of the same factors, our findings contribute to the consensus of studies finding that older faculty receive lower evaluations 7,10$]$.

Related to scientific age is also professional rank; we observed that full professors tended to get higher ratings than both assistant and associate professors, contrary to what we would expect given that younger faculty receive higher ratings. Assistant professors tended to be scientifically younger, whereas full professors tended to be older (shown in S8 Fig). This suggests the relationship between seniority and SET ratings are not necessarily linear, and that those faculty with experience, though perhaps not too much seniority, tend to do best. One past study compared teaching from non-tenured instructors and tenure/tenure track faculty found that non-tenured instructors had stronger evaluations 56]. However, there is little research examining SETs across tenure ranks (assistant, associate, full). Common wisdom suggests that teaching benefits from experience but evidence suggests that past a baseline level of experience, students generally rate younger professors more highly over more senior and experienced faculty. However, younger professors may more readily relate to students or employ more recent pedagogical techniques. Moreover, the requirements, demands, and roles of faculty change over the course of their career, and teaching may be de-emphasized during certain career stages.

\section{Classroom characteristics}

The strongest negative relationship we observed was between overall teaching quality and ratings of class difficulty. Every point increase in difficulty rating (where five is most difficult, and one is easiest) was associated with a drop of nearly half a point in overall quality. This finding is consistent with past studies identifying a negative relationship between difficulty and quality ratings in traditional SETs [57 and on RateMyProfessor.com [46,57,58. One interpretation of this finding is that RateMyProfessor.com is a site used by students to complain about difficult courses and low grades, but overall teaching quality scores are actually somewhat skewed towards higher ratings, with median ratings of 3.6 for the matched dataset. Others have suggested that students have varying definitions of "difficulty". For example, in some studies of SETs, difficulty was associated with perceptions of "fairness" in the course [57,59]; similar effects were observed on RateMyProfessor.com 37. Other scholars have found that clarity of course material and expectations are also important factors of student's ratings of difficulty when posting reviews 36, 58. The form for posting a review on RateMyProfessor.com is vague, and so there are boundless interpretations of the difficulty scale, which we cannot directly examine. However, tags associated with low teaching quality (Fig. 1.C) tended to relate to quantity and type of course material and grading ("tough grader", "lecture heavy", "lots of homework", "test heavy").

Ratings of prior interest almost mirrored those of difficulty, and were the second largest positive correlate with overall teaching ratings; each additional point in student interest was associated with 0.36 point higher ratings. Past studies found similar results when investigating SETs [60 and RateMyProfessor.com [46], though generally little research has been conducted examining the effect of student's prior interest. Under the U.S. liberal arts model of higher education, many instructors will teach courses containing a mixture of students with radically different interest levels in the curriculum, from majors in the subject field to students fulfilling general education credits. This dynamic may similarly affect SETs. Indeed, there is some, if limited, evidence that elective courses (which are freely chosen by the student) often receive better student ratings than required courses [61. Faculty who teach required or general-education courses may be at a systematic disadvantage during performance evaluations if they are subject to the prior interests of their students. However, there 
are also difficulties with interpreting the rating of "prior interest" because it assumes that the student is aware of their true interest in a course at the time of posting their review, and that this measure is somehow indicative of their intrinsic interest in the subject. As with the "chili pepper", ratings of interest may instead reflect a halo effect, such that a student's rating of "interest" (or other teaching-related categories) is more closely related to their opinion of the professor than the course material.

We observed that faculty whose reviews mentioned a teaching assistant (TA) received lower ratings than those where no TA was mentioned. The presence of a TA is our best (though highly flawed) proxy for whether an instructor teaches large courses as TAs are typically employed for larger classes (though not in all cases, and with variations by discipline and university context). Our finding is however consistent with past studies that observed a small but significant negative effect between class size and SET ratings [4,62,63. However, it is difficult to disentangle the extent that the TA in RateMyProfessor.com reviews indicates of the course size, or whether students only mentioned TAs when they were a negative aspect of the course.

\section{University characteristics}

Affiliation with public universities was related with lower ratings than affiliation with private universities, by about 0.08 points of overall quality. One reason for this small difference might be that faculty at private universities have been found to give, on average, higher grades to their students 64 and this higher expected grade may positively influence subsequent evaluations 65. However, the difference we observed might also emerge from the distribution of contextual factors across public and private universities. For example, the sample of private colleges may include many smaller or liberal-arts colleges hosting more faculty in the Humanities and Social Sciences.

We also examined the research classification of universities, but we observed only trivial differences between R1 and non-R1 universities. There is little research examining differences in SETs across different university types, whether between public and private universities or between research-focused and teaching-focused. Part of this may be because aggregating SETs across institutions is difficult due to their sensitivity. The formats of SETs are also likely to vary between institutions making comparisons between universities difficult. Here we find little difference in ratings of teaching quality based on university types, but more work is needed to understand the role of institutional context in teaching.

\section{Discipline}

We observed distinct trends in student's ratings of teaching by discipline; faculty in the Humanities tended to be the highest rated, whereas faculty in Engineering and Social Science tended to have the lowest ratings. These findings are consistent with past studies of discipline and teaching evaluation. For example, faculty teaching traditionally quantitative disciplines were found to receive lower ratings, an effect that was observed for traditional evaluations 13, 17] and on RateMyProfessor.com [46]. However, whereas Social Science is not typically associated with quantitative courses, we observed that teaching ratings for faculty in Social Science tended to only be trivially higher than faculty in Engineering. One reason for this discrepancy may be that the high-level classifications used in this study mask the true heterogeneity of disciplines and courses and don't easily allow for "quantitative" / "not quantitative" distinctions. However, we also observed that regression estimates for disciplinary effects differed from the simple average of ratings by discipline, for which Natural Sciences actually have the lowest median rating (S5 Fig); this suggests that some of some of the disciplinary differences might be explained by contextual factors such as the distribution of faculty 
demographics, classroom, and university characteristics across disciplines. For example, in our preliminary analysis of the interaction between gender and discipline, we observe differences across fields. More thorough work is necessary to understand discipline and course topic relates to teaching and SETs; in particular, a more comprehensive and thorough statistical analysis according to discipline, combined with a more fine-grained disciplinary classification could provide additional insight into the relationship between discipline and SETs.

\section{Research-teaching nexus}

Applying several different techniques, we observed little to no relationship between indicators of research performance and ratings of overall teaching quality on RateMyProfessor.com. In other words, we observed evidence consistent with a neutral research-teaching nexus, as observed in several past studies 34,66 69. In the study most similar to our own, a weak correlation was observed between ratings on RateMyProfessor.com and journal publication count [30, however the study examined only faculty affiliated within Marketing departments. Other studies have observed positive research-teaching nexus between SETs and research productivity under certain circumstances 70,71, but generally, empirical evidence is lacking 34]. The results from our analysis contribute to the consensus of a neutral relationship between research and teaching.

The research-teaching nexus is complicated, and difficult to assess. Evidence for a null model tend to use SETs or an equivalent indicator to measure teaching performance. Studies also tend to use output-based bibliometric indicators to measure research performance; our study also only examines recent research output, whereas longer time-scales of output may correlate more strongly with teaching. Such indicators have been called into question as being improper or inadequate tools that don't measure true teaching or research performance $42,72,73$.

The research-teaching nexus, if it exists, may be intangible or may not manifest in performance measures. Rather than further attempting to empirically verify the existence of the research-teaching nexus using quantitative tools, qualitative

methodology may prove more useful to explore perceptions of the nexus $24,27,74$.

Such approaches could reveal the extent to which faculty believe the nexus exists, what they believe about the nature of the nexus, and how the nexus has evolved with increasing faculty time constraints 31,32,75]. Moreover, if the relationship between research and teaching is held as a value of academia, then researchers and administrators should explore ways of actively promoting the research-teaching nexus 66].

\section{Limitations}

Our study is subject to several limitations. First, we note that we conducted a preliminary and exploratory study using observational data and as such our methods were not pre-registered and our analysis is subject to issues of multiple comparisons.

Second, our use of RateMyProfessor.com as a proxy for SETs is a clear limitation, as reviews on the website suffer from issues of external validity [58] and selection bias, wherein students with extreme opinions are likely to be the ones to post reviews. The website has also endured criticism that reviews not align with effective teaching 36]. While traditional SETs are intended for internal use for faculty evaluation and improvement, the primary purpose of RateMyProfessor.com is to help students select courses; the expectations and rating criteria of each likely diverge. Despite these issues, ratings on RateMyProfessor.com have been found to correlate with traditional SETs (see S2 Text). Similarly, quantitative measures of teaching and research do not capture quality. The indicators used in this analysis are also limited in that they capture only 
recent performance - an artifact of Academic Analytics - more insights may be gained by examining the historical trends of professor's research or teaching performance.

Third, we were limited by the evolving nature of our data sources.

RateMyProfessor.com has undergone many changes since its inception, including changes to the features and indicators provided to raters. While we limit our analysis to relatively recent reviews, during this time certain indicators (such as the separate measures of "Clarity" and "Helpfulness" and "Interest", as well as the "Chili Pepper") were removed (see S1 Text).

Fourth, by limiting our analysis to tenure and tenure-track faculty in the United States, our analysis excluded contingent and other non-tenure track faculty who comprise over 70 percent of the U.S. [76 and more than 50 percent [77 of Canadian faculty appointments, as well as graduate student instructors who may teach a large proportion of courses 78 . These populations face unique challenges 79 , 80 that remain unaddressed in the present study. Moreover, these results are limited to faculty within the United States, and so our findings may not generalize to other national contexts.

Finally, our analysis was also limited by the record-matching algorithm which did not capture all relevant faculty. The parameters for record matching favored precision over recall, so the number of matched faculty are a conservative sampling of the population. Additionally, there were many professors who simply did not appear on RateMyProfessor.com or in Academic Analytics, and so do not appear in the present analysis. Given that there is no known list of all U.S. faculty, it is difficult to assess the extent to which the matched faculty were representative of U.S. tenure and tenure-track faculty as a whole.

\section{Conclusion}

This paper provided an exploratory analysis of the factors relating to online ratings of teaching quality and their relationship to research productivity. We constructed a novel dataset by matching records of known tenure and tenure-track faculty from Academic Analytics with individuals listed on RateMyProfessor.com. We assessed the effect of the demographics of the teacher, characteristics of the class, of the university, and of the discipline. Faculty tended to receive higher ratings when they were rated as attractive (having the "chili pepper" on RateMyProfessor.com), when they were male, when they were young, when they were not mentioned as having an accent, and when they were full and associate professors. Faculty tended to receive lower ratings when the course was difficult, when there was little student interest, or when a teaching assistant was mentioned. We observed some evidence that faculty in private universities were rated slightly higher than those from public universities, but overall university characteristics were weakly related to ratings of teaching. Faculty from the Humanities tended to be rated most highly, followed by those in the Medical Sciences, Natural Sciences, Social Sciences, and finally Engineering.

In addition to demographic and contextual factors, we also assessed the presence and extent of the so-called research-teaching nexus, the relationship between research and teaching. Comparing indicators of recent publications, recent citations, current grant funding, and professional awards, we found evidence consistent with a neutral nexus, or no relationship between research and teaching.

These results and data provide a foundation for future large-scale analysis of SETs and of the research-teaching nexus. Future work could delve deeper into this data, comparing patterns of student ratings of teaching across more disciplines, university types, course levels, and even specific departments. RateMyProfessor.com also offers a trove of text data from student comments; content analysis and text mining of these data could reveal key insights to the underlying factors of student's ratings, such as 
gendered language and attitudes 51]. This text data can be leveraged to identify other faculty characteristics, such as their self-disclosed or perceived LGBTQ+ status, allowing study into the unique challenges faced by those faculty of different sexual orientations and gender identities 81 83. The current dataset could also be enriched with survey data relating to time spent on service-related activities or more detailed bibliometric indicators from the Web of Science or Scopus. It is our hope that the present analysis is the first of many to explore broad trends in the nature of quantitative performance measures across disciplinary, university, and classroom contexts.

Despite controversy, student evaluations of teaching dominate faculty evaluation across the United States; given their continued importance, it is important to understand what factors contribute to these scores and how these factors differ between institutional and disciplinary contexts. Our results build on past research that demonstrates the biases, limitations, and deficiencies of SETs. The confluence of research should cause the higher education community to consider whether the student evaluations of teaching should be discounted, rehabilitated, or done away with all together. 


\section{Supporting information}

S1 Text Values no longer used by RateMyProfessor.com.

Before summer, 2017, when a user left a review for a professor on

RateMyProfessor.com, they were prompted to select their interest level prior to

attending class. The available interest levels were grouped into five ordinal categories, ranging from "Low" at the bottom to "It's My Life" at the top (further description available in S3 Table and S2 Table. The selected interest level was then displayed on each user's review. Since the summer of 2017, this feature is no longer present on the site. We however have data on student interest for every review beforehand, and so we do not exclude this variable form our analysis.

Clarity and helpfulness were two other quantitative metrics in use by RateMyProfessor.com, but were recently removed from the site. Though we have these data, we exclude them from our present analysis because past research, and our own analysis, demonstrates that they are strongly correlated with overall quality [40].

The "chili pepper" or "hotness" rating, while never explicitly defined as such, was implicitly associated with the physical attractiveness of the professor. This rating was removed from RateMyProfessor.com as of 2018, however, it was present throughout the period of data collection and so we include it in our analysis.

S2 Text Validity of Academic Analytics and RateMyProfessor.com. As Academic Analytics is used by more institutions, its validity has been called into question 84. However, these allegations have largely been anecdotal given that the data is proprietary and thus not available for public scrutiny. A large-scale validation exercise remains necessary to thoroughly assess the accuracy of research indicators in AA2017. One such analysis has already been conducted on CrossRef - the source of AA2017's publication and citation network 85]; this analysis found considerable overlap of both citations and publications with more widely accepted research evaluation databases such as Scopus and Web of Science. Our own small-scale analysis, compared the counts of items listed on the CVs of professors to their counts listed in AA2017 and demonstrated reasonably accurate coverage of publications. In light of this evidence, we believe that AA2017, while not thoroughly vetted, is sufficient for large-scale analysis. An advantage of using AA2017 is that they collect data for faculty in a variety of disciplines, potentially leading to greater coverage of Humanities and Social Sciences than traditional bibliometric sources such as Scopus and Web of Science 86.

Concerns have been raised over the validity of RateMyProfessor.com. The website lacks external validity as a result of its open and anonymous nature, allowing students to rate a course on their first day of attendance, or even years after 36. Additionally, the content on the site is entirely user-generated with little to no gatekeeping to ensure that real students are in fact reviewing real professors for courses they actually took. One result of this is entirely fabricated records; for example, RateMyProfessor.com included a profile for "Albus Dumbledore, professor of transfiguration at Hogwarts School of Witchcraft and Wizardry", a popular fictitious character from the Harry Potter franchise, who had 143 student ratings at the time of writing. By merging records with Academic Analytics, which contains a known list of active tenure and tenure-track faculty, we mitigate the impact of fabricated or otherwise misleading profiles. Despite criticism, evidence supports that RateMyProfessor.com ratings correlate with traditional student-evaluations of teachers [37,40, 87], suggesting that findings from our analysis are likely to generalize to other faculty evaluations.

S3 Text Representativeness of matched vs. unmatched records in Academic Analytics. 
S10 Table details descriptive information for individuals from the Academic Analytics dataset (AA2017) who were matched versus not matched with records in RateMyProfessor.com. The unmatched statistics includes only tenure and tenure track faculty. This comparison allows us to assess the extent of bias in our matching process.

The largest differences we observed between the matched and unmatched dataset relate to the discipline of faculty and the control of the university (public vs. private), and the rank of the professor. Under the assumption that all students in a course are equally likely to leave their instructor on RateMyProfessor.com, professors who teach more classes and are exposed more students would be more likely to appear in RMP2018. Given this, one possible contributing factor to differences between matched and unmatched data is the relative exposure of these faculty; this exposure will likely differ across disciplinary and university contexts. For example, medical scientists were underrepresented in the matched data; a cursory investigation of CVs from these faculty revealed that while they often held affiliations with university medical schools, they focus on research and teach comparatively little. Similarly, public universities tend to be much larger, on average, than private universities, and so faculty are likely to teach larger classes and be exposed to more students, leading to an over-representation of public schools. Even within a university, associate faculty may have greater teaching loads than full faculty, and so would be more likely, on average, to have a review on RateMyProfessor.com, resulting in an over-representation of associate faculty in the matched data. Moreover, since S10 Table includes only tenure and tenure-track faculty, departments that use lecturers to teach large courses may be underrepresented; our analysis only concerns tenure and tenure-track faculty and so while lecturers may have many students, they are excluded from analysis.

We observed only small differences in research indicators between matched and unmatched faculty; research performance may differ by faculty's institutional affiliation, seniority, and discipline; we partially control for this last factor through a simple field-normalizing, but this form of normalization is flawed [88]. Minor differences that we observed in indicators of research performance between and unmatched faculty may have resulted from the differences in the distribution of these faculty across university, disciplinary, and professional contexts.

\section{S4 Text Representativeness of matched vs. unmatched records in RateMyProfessor.com.}

Past analyses of faculty rating data from RateMyProfessor.com have typically followed one of two approaches: in the first approach researchers examine large samples of profiles sampled from the website $11,46,89$; however, results from this approach may be confounded by fake profiles and by mixing profiles of full-time research faculty with those of graduate instructors, lecturers, or part-time faculty. Other studies have instead examined smaller known population, typically limited to faculty from a small number of departments and universities whose profiles can be manually extracted from

RateMyProfessor.com [6, 30, 36, 39, 40]; however, these studies may lack external validity. The present study attempted a balance between these approaches by examining a large and diverse set of known tenure and tenure-track faculty.

S9 Fig shows how ratings from RMP2018 differ between the population of matched and unmatched faculty. Matched faculty tended to have slightly lower ratings of overall quality $($ median $=3.7$, mean $=3.5)$ than unmatched faculty $($ median $=4.0$, mean $=$ 3.8). Matched faculty tended to be rated as more difficult (median $=3.2$, mean $=3.2$ ) than unmatched faculty (median $=2.8$, mean $=2.9$ ). Ratings of student interest were roughly the same between matched and unmatched faculty. The distribution of the number of comments was highly skewed, though matched faculty tended to have more comments $($ median $=8$, mean $=10.2)$ than unmatched faculty $($ median $=7$, mean $=$ 
9.5). However, these values include only individuals who had 25 or fewer reviews, as was used in the main analysis. The distribution of reviews tended to be highly positively skewed, with a maximum value of 268 for matched faculty, and 2,365 for unmatched faculty.

The largest difference between matched and unmatched faculty in RMP2018 was that a larger proportion of unmatched faculty had a chili pepper (30.5 percent with) than matched faculty (19.9 percent with). Assignment of the chili pepper, indicating the attractiveness, is associated with scientific age (see $\mathrm{S} 4 \mathrm{Fig}$ ); one possible reason for this difference may be that matched faculty are older than unmatched faculty, however since RMP2018 does not record age this cannot be assessed. Matched faculty more often were mentioned as having an accent (8.7 percent) than unmatched faculty (5.4 percent) though this difference was relatively small. Matched faculty were also more likely to have had a teaching assistant mentioned (5.3 percent) compared to unmatched faculty (1.1 percent).

Differences between matched and unmatched faculty likely resulted from differences in university, disciplinary, and professional contexts that shape who is most likely to be reviewed. Since we matched RMP profiles with records from AA, matched faculty were all tenure and tenure-track faculty at research-oriented universities. The unmatched RMP profiles however contained many faculty from small liberal arts colleges, community colleges, and other teaching-oriented institutions; these institutions may have had different faculty demographics than larger research-oriented institutions. Related to institutional context is discipline - for example, larger research-oriented universities may have been able to host more faculty and students in disciplines requiring lab space or special facilities (e.g.: medicine) or disciplines requiring accreditation (e.g.: civil engineering). Some of these disciplines will be more likely to use teaching assistants. There are differences in faculty demographics between disciplines, based on gender and nationality 90,92 which might relate to mentions of accent. Unmatched faculty consisted of many non-tenure faculty and so would include part-time faculty, non-research instructors, and graduate instructors. These various teacher roles may be associated with distinct demographics and teaching contexts, which may have contributed to the observed differences between matched and unmatched faculty. 
S1 Fig.

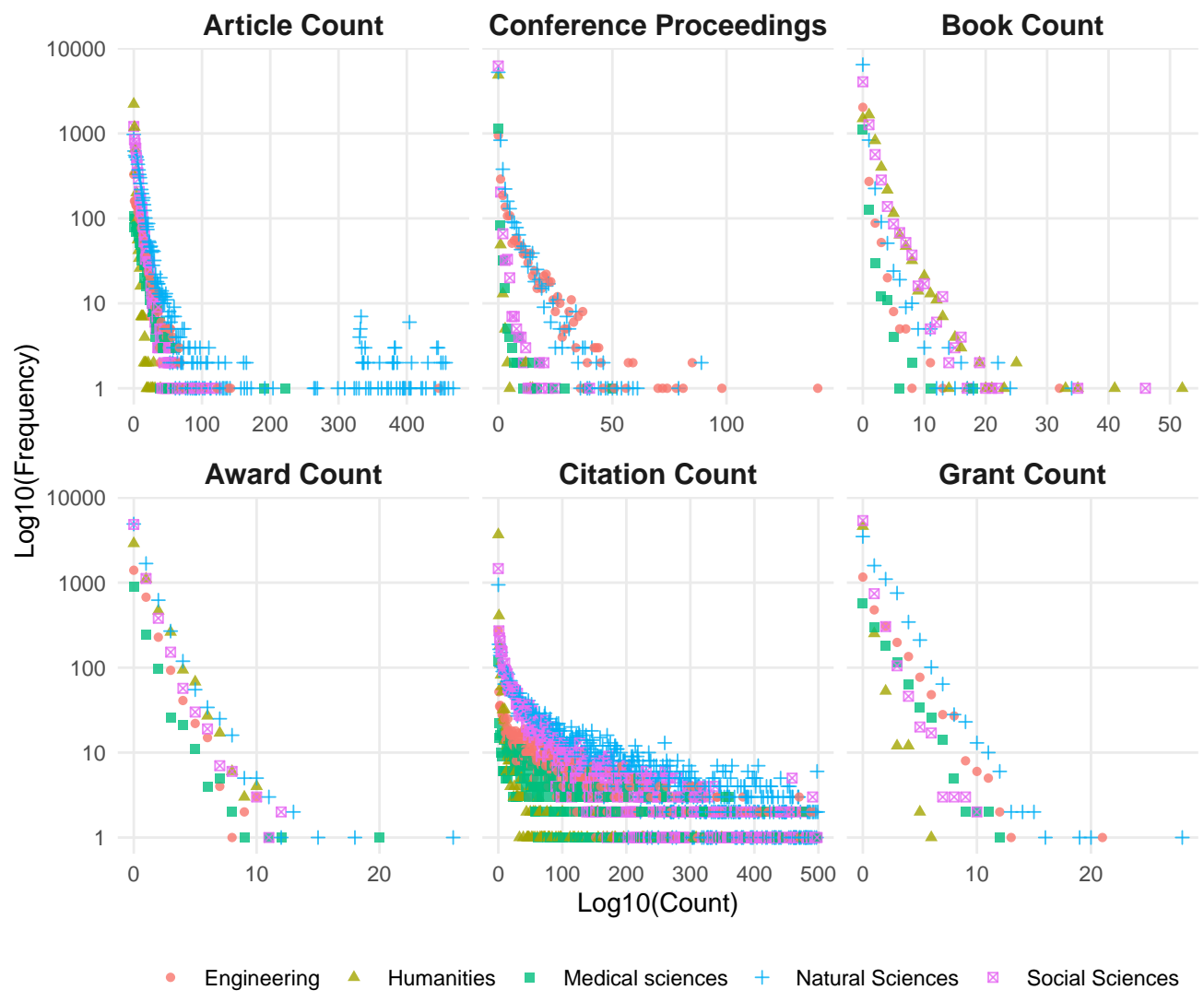

Distribution of research indicators. A point-based histogram of frequencies of research indicator values in the dataset placed on a LogLog scale. Each point plots the frequency of professors with a given "count" of research items. Non-normalized raw counts are used. Points are grouped by discipline, specified by color and shape. Aggregate values by discipline can be found in S11 Table. 
S2 Fig.

Publications

Awards

Citations

Grants

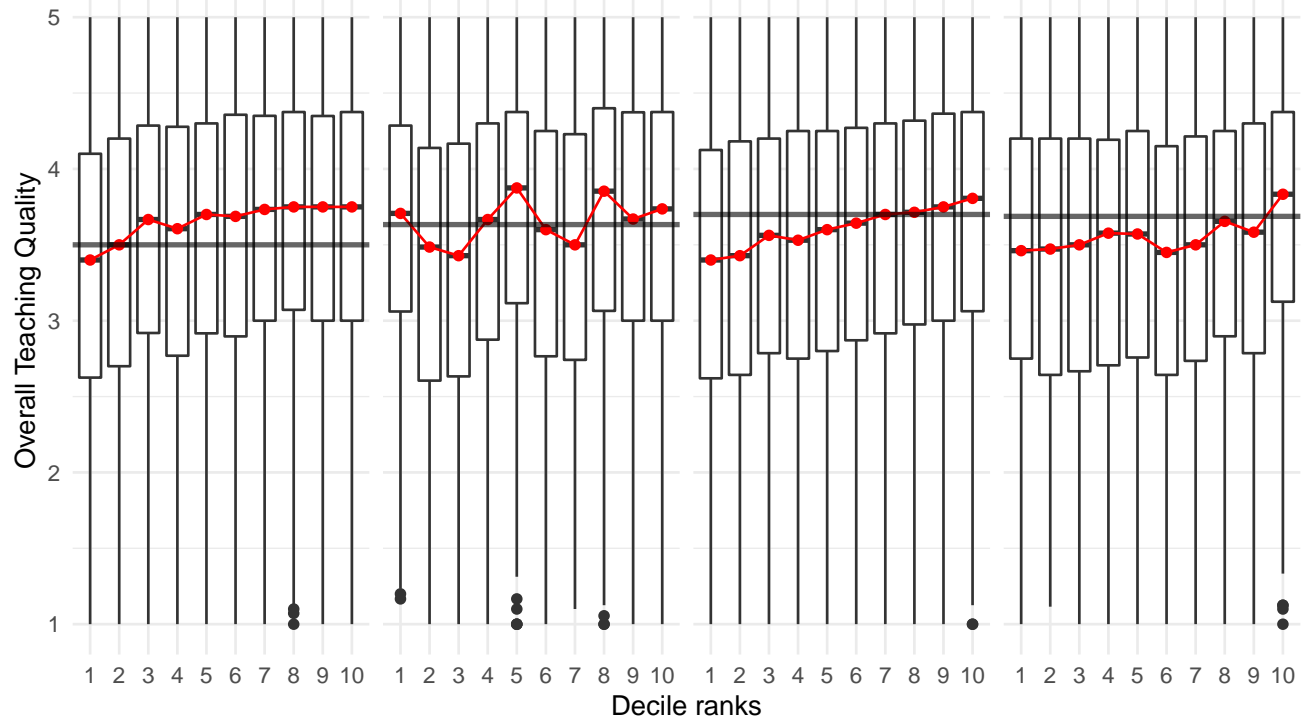

Ratings of teaching quality by research performance. Boxplots of ratings of overall teaching quality for faculty having a positive non-zero value for field-normalized research indicators. Indicator performance is binned into deciles (x-axis). The horizontal grey line is the median for faculty with a value of zero in each indicator. The red line corresponds to the median rating of overall teaching quality for faculty in each decile bin. 
S3 Fig.

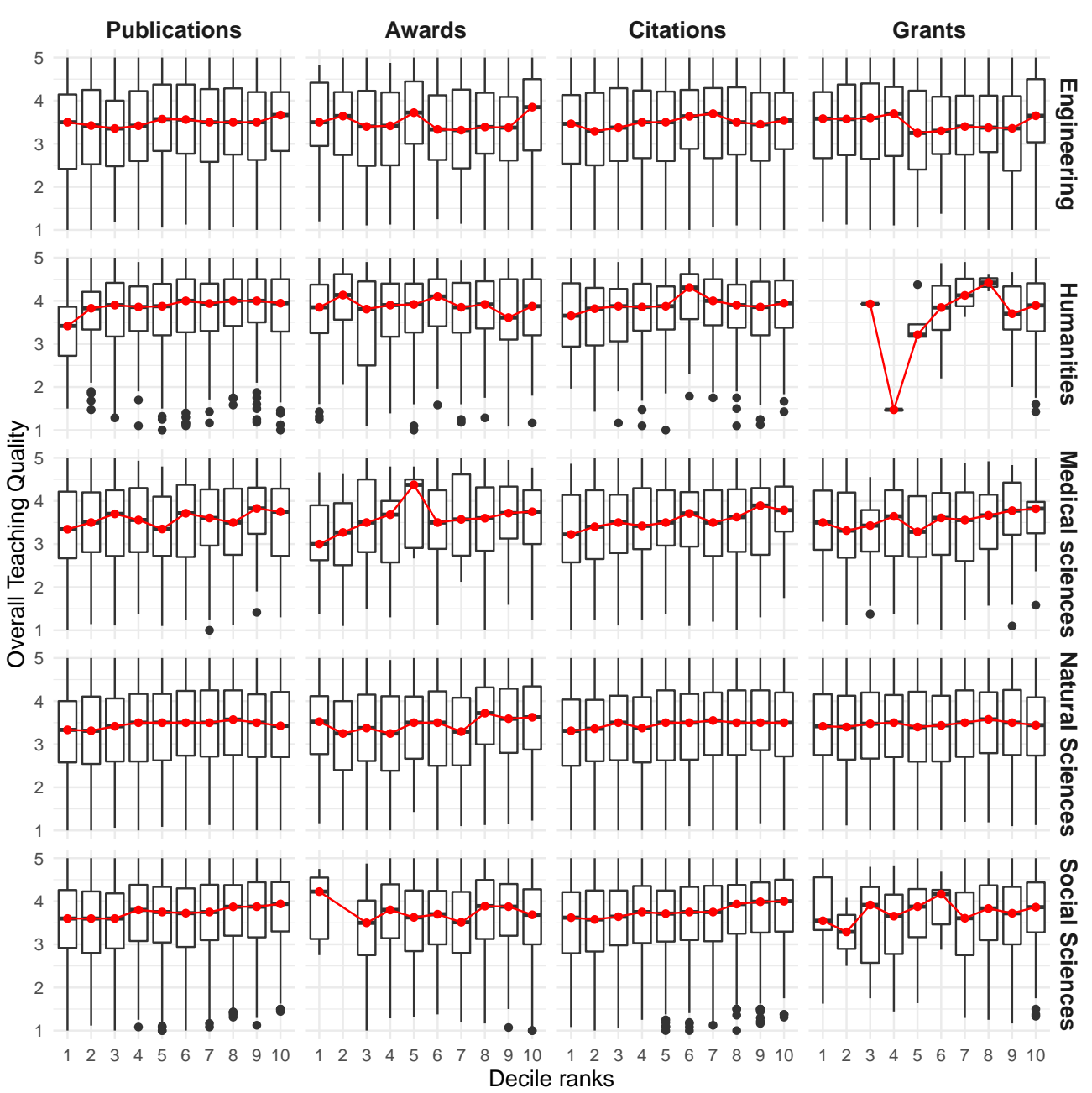

Ratings of teaching quality by research performance and discipline.

Boxplots of ratings of overall teaching quality for faculty having a positive non-zero value for field-normalized research indicators. Indicator performance is binned into deciles (x-axis), repeated for faculty in each of the five discipline categories. The red line corresponds to the median rating of overall teaching quality for faculty in each decile bin. 
S4 Fig.

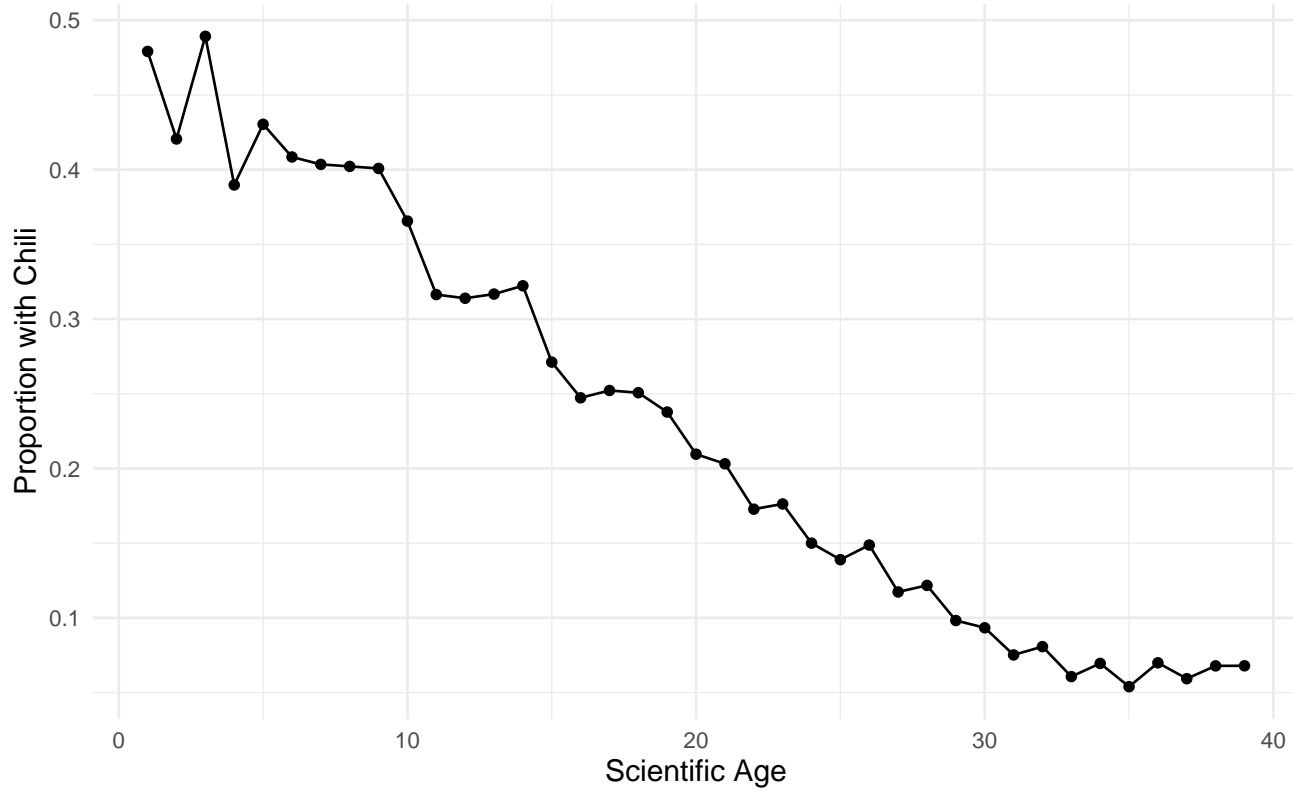

Younger faculty more often assigned chili pepper. The proportion of faculty in the matched dataset that were assigned a chili pepper (y-axis), implicitly suggesting attractiveness, by scientific age (x-axis). 
S5 Fig.

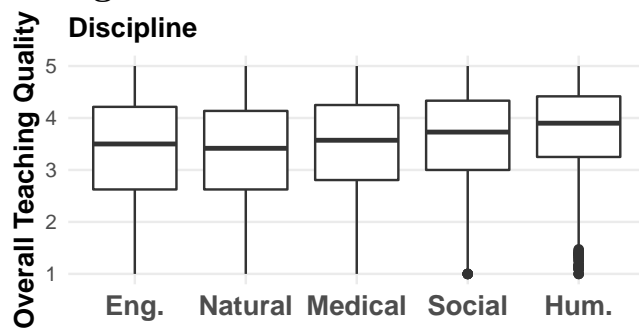

Has chili pepper

2
4

3

1

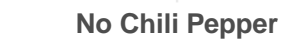
Univeristy Type

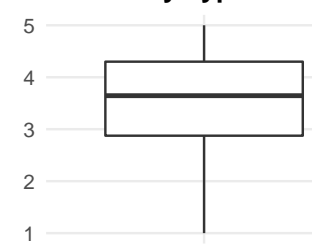

Not R1
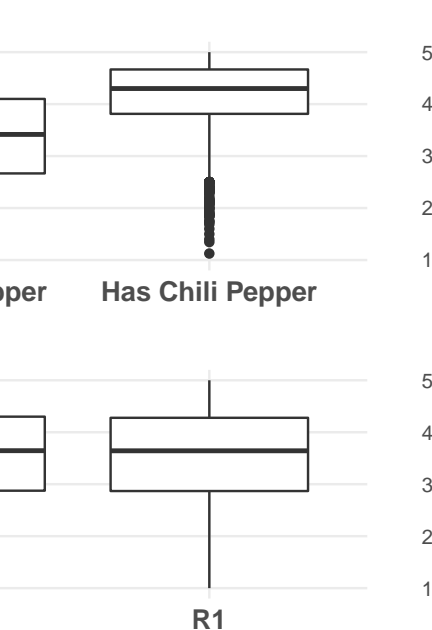

Professor rank

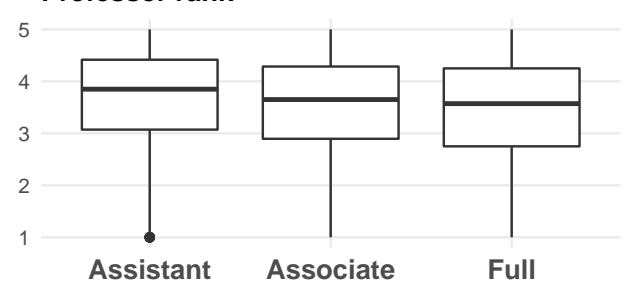

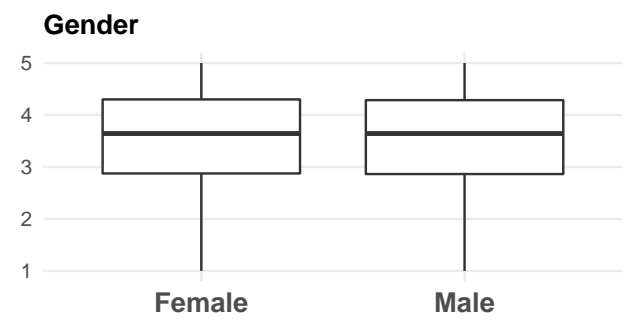

Inferred Race

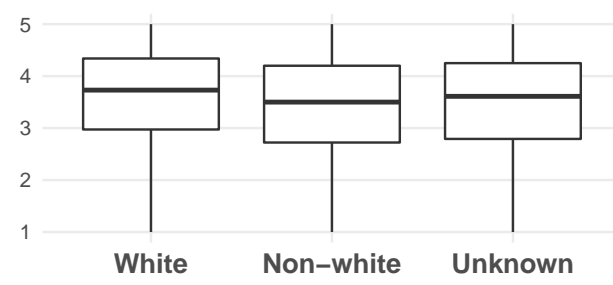

University Control

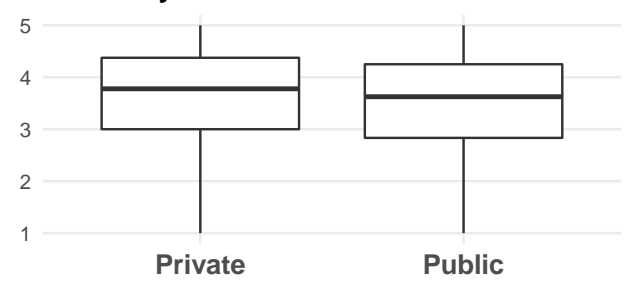

Distribution of teaching quality across categorical variables. The distribution of ratings of overall teaching quality (y-axis) for values of each categorical variable (x-axis) from the matched dataset. Includes discipline, gender, whether the faculty has a chili pepper, inferred race, the university type, the university control, and the professor's rank. 
S6 Fig.

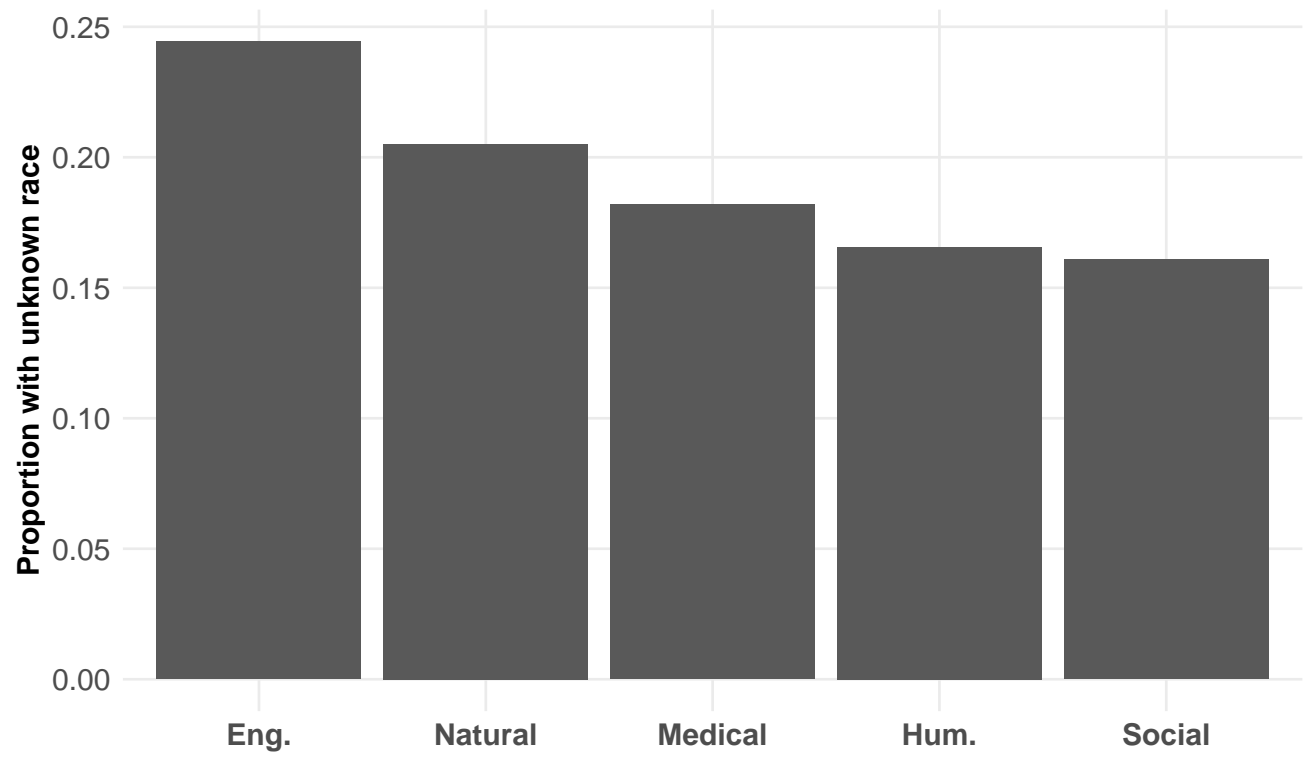

Proportion of faculty with unknown race by discipline.

S7 Fig.

Prop. Is Non-white

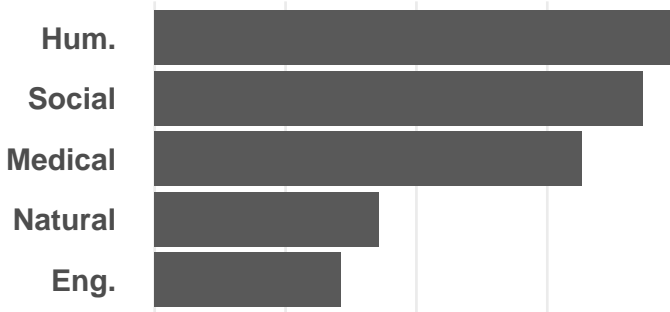

Prop. has mentioned accent

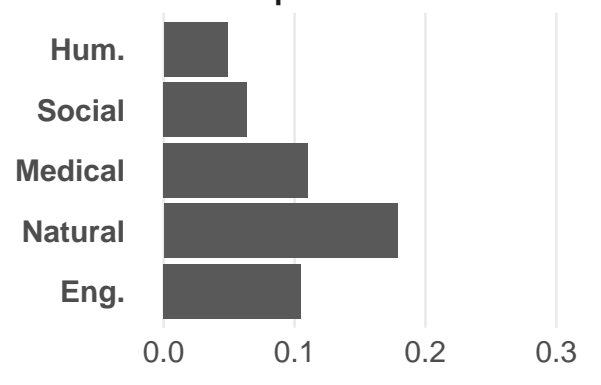

Faculty demographics by discipline.

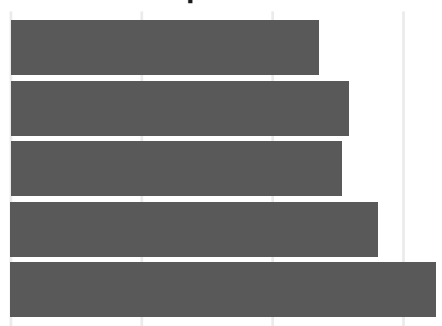

Prop. has mentioned TA

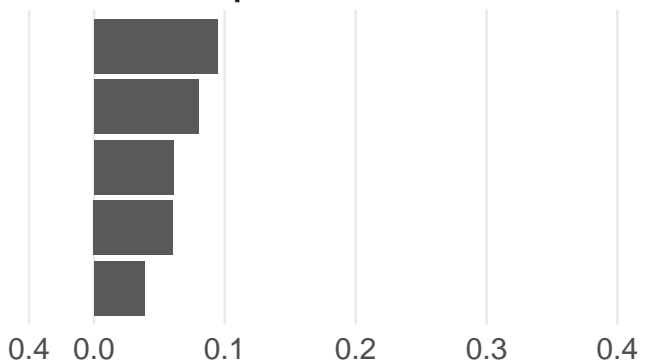


S8 Fig.

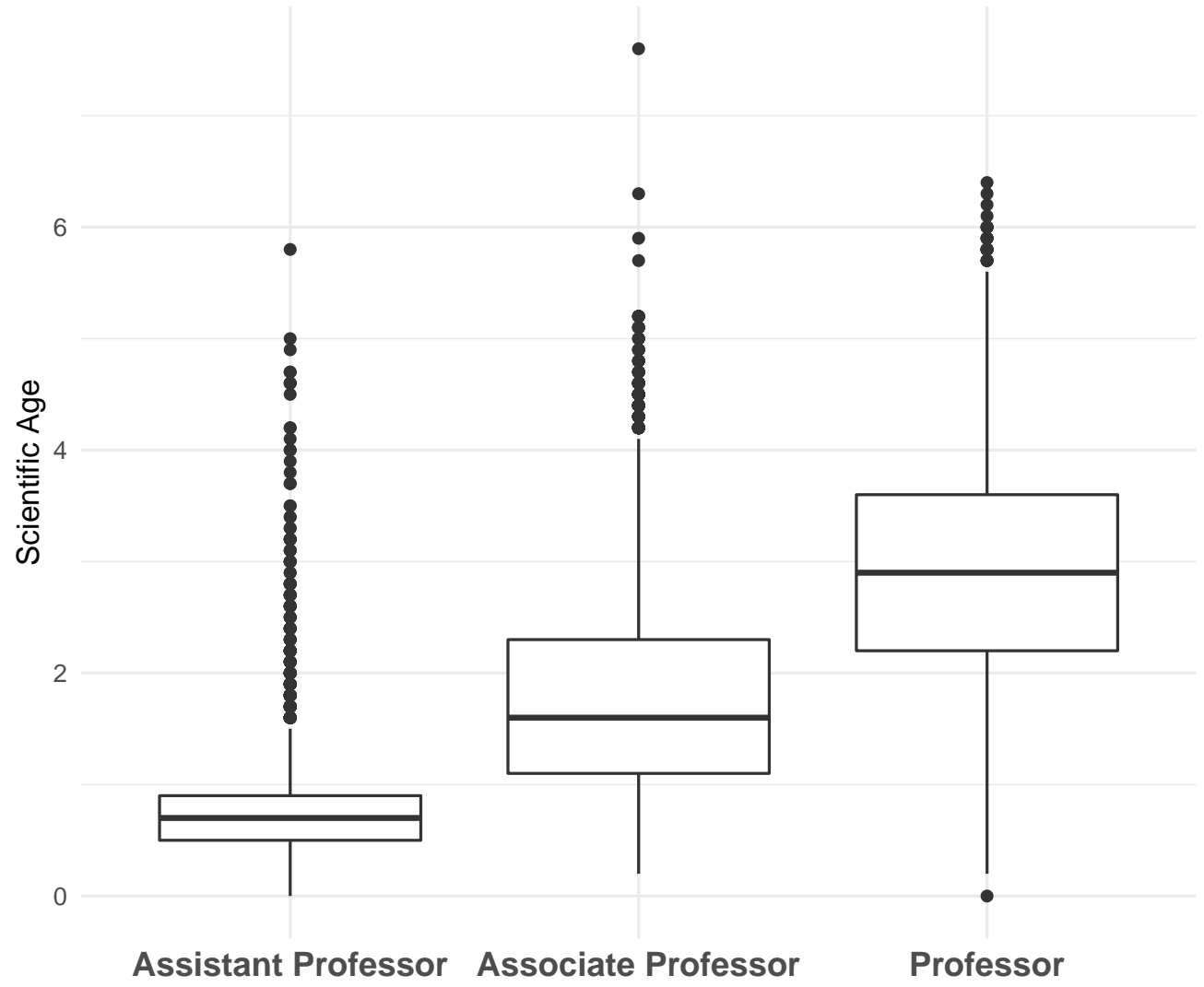

Distribution of faculty scientific age by rank. Boxplots for the distribution of scientific age (years since earning $\mathrm{PhD}$ or other terminal degree) and the rank of faculty, ${ }^{804}$ as indexed in AA2017. 
S9 Fig.
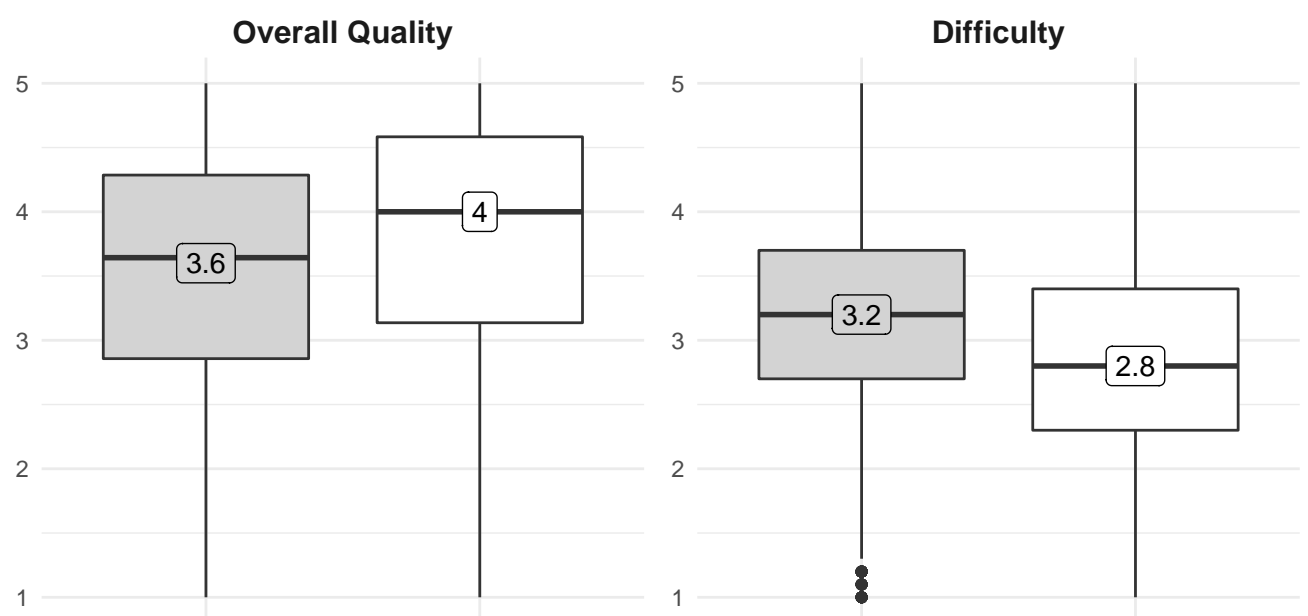

Interest

Number Comments

5

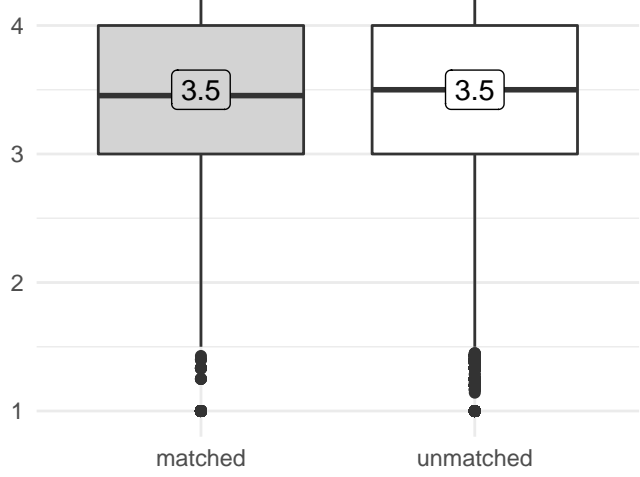

25

20

15

10

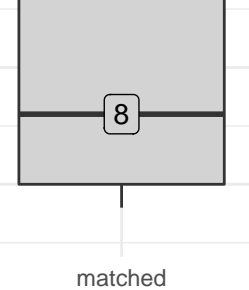

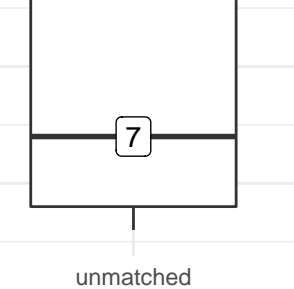


S1 Table Description of relevant variables from Academic Analytics 2016

dataset. Source indicates where the variable was collected by Academic Analytics.

"Submitted" indicates that the variable was given to Academic Analytics by the institution.

\begin{tabular}{|c|c|c|}
\hline Variable & Source & Description \\
\hline Person name & $\begin{array}{l}\text { Submitted; Cross- } \\
\text { Ref, Institutional } \\
\text { Websites }\end{array}$ & Full name of individual, as collected or submitted to Academic Analytics. \\
\hline $\begin{array}{l}\text { Institution } \\
\text { Name }\end{array}$ & $\begin{array}{l}\text { Submitted, Institu- } \\
\text { tional Websites }\end{array}$ & Name of the institution in which the individual holds an affiliation \\
\hline Degree Year & $\begin{array}{l}\text { Submitted; Institu- } \\
\text { tional Websites; CVs }\end{array}$ & $\begin{array}{l}\text { Year in which the individual obtained their terminal degree (usually a } \\
\text { doctorate) }\end{array}$ \\
\hline $\begin{array}{l}\text { Program } \\
\text { Name }\end{array}$ & $\begin{array}{l}\text { Submitted; Institu- } \\
\text { tional websites }\end{array}$ & $\begin{array}{l}\text { The name of the program to which the individual is affiliated, usually } \\
\text { the name of their home department }\end{array}$ \\
\hline Level 1 Name & Assigned by AA & $\begin{array}{l}\text { Disciplinary classification of the individual, one of } 172 \text { low-level classifi- } \\
\text { cations created by AA and assigned based on the individuals' program } \\
\text { affiliation }\end{array}$ \\
\hline Article Count & CrossRef & $\begin{array}{l}\text { Count of peer-reviewed journal articles published in } 2013,2014,2015 \\
\text { and } 2016 . \text { For coauthored articles, all authors are credited }\end{array}$ \\
\hline $\begin{array}{l}\text { Conf. Pro- } \\
\text { ceeding Count }\end{array}$ & CrossRef & $\begin{array}{l}\text { Count of indexed conference proceedings published in } 2013,2014,2015 \text {, } \\
\text { and } 2016 \text {. For coauthored articles, all authors are credited }\end{array}$ \\
\hline $\begin{array}{l}\text { Citation } \\
\text { Count }\end{array}$ & CrossRef & $\begin{array}{l}\text { Citations to articles and proceedings that were published in } 2012,2013 \text {, } \\
\text { 2014, 2015, and 2016; data is derived from the CrossRef citation-linking } \\
\text { network. Self-citations are included }\end{array}$ \\
\hline Book Count & 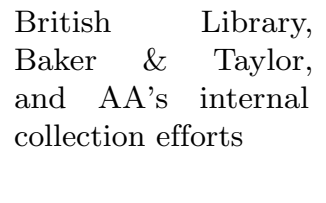 & $\begin{array}{l}\text { Count of time appearing as author, co-author, editor, co-editor, and } \\
\text { translator of books published in 2006-2016 (inclusive). Introductions, } \\
\text { forewords, afterwards, and citations are not included in the } 2014 \text { Aca- } \\
\text { demic Analytics dataset. Due to their limited use of DOIs, chapters are } \\
\text { limited. }\end{array}$ \\
\hline Grant Count & $\begin{array}{l}\text { Publicly available } \\
\text { databases and FOIA } \\
\text { requests }\end{array}$ & $\begin{array}{l}\text { Count of grants data from } 13 \text { federal agencies and two non-federal } \\
\text { sources matched to principal investigators. For NIH, NSF and NOAA } \\
\text { grants, matching includes co-principal/multi-principal investigators }\end{array}$ \\
\hline Award Count & $\begin{array}{l}\text { AA's Internal collec- } \\
\text { tion efforts }\end{array}$ & $\begin{array}{l}\text { The count of awards among honorific awards from } 821 \text { governing societies } \\
\text { that are open to all people in a discipline, sub discipline, or a large } \\
\text { subset of people at a national or international level, and that can be } \\
\text { matched to individuals appearing in the Academic Analytics dataset }\end{array}$ \\
\hline
\end{tabular}


S2 Table Description of relevant variables extracted from RateMyProfessor.com reviews.

\begin{tabular}{ll}
\hline Variable & Description \\
\hline Comment & $\begin{array}{l}\text { An optional textual review of the teacher -in the newest } \\
\text { iteration can contain up to } 350 \text { characters }\end{array}$ \\
Course & $\begin{array}{l}\text { A code indicating the course that the student took with } \\
\text { the teacher. Can be entered manually or selected from } \\
\text { a list of options from a history of course codes used in } \\
\text { previous reviews of the professor }\end{array}$
\end{tabular}

Overall quality

A rating of the overall quality of the professor on an ordinal scale of 1 to 5 . When posting a review on the RMP website the user is prompted with the question "How would you rate this professor as an instructor?". A rating of 1 indicates that the professor is poor quality while a rating of 5 indicates high quality.

Level of difficulty A rating of the level of difficulty of the professor on an ordinal scale of 1 to 5 . When posting a review a user is prompted with the question "How hard did you have to work for this class?". A rating of 1 indicates that the course is not difficult whereas a rating of 5 indicates that the course is very difficult.

Tags

The user is prompted to select at most three of a list of 23 predefined tags that describe the characteristics of the professor and their course

Interest

A legacy variable, this feature appears to have been removed at some point in the middle of 2017 and no longer features on reviews posted to the website. In older reviews this variable was intended to measure the interest that the student had in the subject of the course on a qualitative ordinal scale containing values of "Low", "Meh", "Sorta Interested", "Really into It" and "It's My Life" 
S3 Table Description of relevant variables extracted from RateMyProfessor.com teacher profiles.

\begin{tabular}{|c|c|}
\hline Variable & Description \\
\hline Name & $\begin{array}{l}\text { Name of the teacher, as listed on the website, added by } \\
\text { the users }\end{array}$ \\
\hline Department & $\begin{array}{l}\text { Department to which the teacher is affiliated as listed on } \\
\text { the website and added by users }\end{array}$ \\
\hline School & $\begin{array}{l}\text { The School that the teacher is affiliated with, added by } \\
\text { users }\end{array}$ \\
\hline Overall Quality & $\begin{array}{l}\text { An average of the individual ratings of a teacher's overall } \\
\text { quality, intended as a general quality indicator. Individual } \\
\text { ratings are on an ordinal scale between one and five, where } \\
\text { one is considered poor quality, and five is considered high } \\
\text { quality }\end{array}$ \\
\hline Level of Difficulty & $\begin{array}{l}\text { An average of the individual ratings of a teacher's level } \\
\text { of difficulty, intended as an indicator of the difficulty of } \\
\text { the teacher's courses. Individual ratings are on an ordinal } \\
\text { scale between one and five, where one is considered easy } \\
\text { and five is considered difficult }\end{array}$ \\
\hline Chili & $\begin{array}{l}\text { Presence of a "chili pepper" on the website, which indi- } \\
\text { cates "hotness", or "attractiveness". When submitting a } \\
\text { review, the user is asked to select between a positive and } \\
\text { negative "hotness" rating. When the number of positive } \\
\text { hotness ratings is greater than the number of negative } \\
\text { hotness ratings, then that professor's profile is marked } \\
\text { with a chili pepper }\end{array}$ \\
\hline Tags & $\begin{array}{l}\text { Individual reviewers can select from at most three of } \\
\text { twenty pre-defined TAGS relating to characteristics of the } \\
\text { professor or the course. These tags are then aggregated } \\
\text { at the level of the professor. While the RMP website } \\
\text { includes counts for the number of times these tags have } \\
\text { been applied, we only capture a Boolean value indicating } \\
\text { the presence of a tag }\end{array}$ \\
\hline
\end{tabular}


S4 Table Results of multiple linear regression model. For binary variables, "false" is always used as the reference level. For Gender, "female" is used as the reference. For race, "Non-White" is used as the reference. For rank, "Assistant" is used as the reference. For Discipline, "Engineering" is set as the reference. For Uni. Control, "Private" is used as the reference. For Uni. Type, "Not R1" is used as the reference. For all research indicators, "Low" is used as the reference. Estimates are listed first, followed by 95 th percentile confidence intervals. Results here are identical to those in Fig. 1.A

\begin{tabular}{lc}
\hline \hline & Dependent variable: \\
\cline { 2 - 2 } & overall \\
\hline Is Male & $0.106^{* * *}(0.084,0.127)$ \\
Scientific Age & $-0.133^{* * *}(-0.147,-0.119)$ \\
Mentions Accent $=$ True & $-0.172^{* * *}(-0.203,-0.142)$ \\
Has Chili Pepper & $0.417^{* * *}(0.393,0.442)$ \\
Rank $=$ Associate & $0.047^{* * *}(0.017,0.076)$ \\
Rank $=$ Full & $0.137^{* * *}(0.100,0.174)$ \\
Race unknown & $0.046^{* * *}(0.019,0.074)$ \\
Race Lilely White & $0.118^{* * *}(0.096,0.140)$ \\
Difficulty & $-0.391^{* * *}(-0.401,-0.381)$ \\
Student Interest & $0.329^{* * *}(0.319,0.339)$ \\
Mentions TA $=$ True & $-0.184^{* * *}(-0.219,-0.149)$ \\
Citedness $=$ Moderate & $-0.024(-0.054,0.006)$ \\
Citedness $=$ High & $-0.033(-0.085,0.018)$ \\
Output $=$ Moderate & $0.034^{*}(-0.001,0.069)$ \\
Output $=$ High & $0.022(-0.033,0.077)$ \\
Grants Held = Moderate & $-0.002(-0.026,0.023)$ \\
Grants Held $=$ High & $0.031(-0.024,0.086)$ \\
Awards Won $=$ Moderate & $0.010(-0.011,0.031)$ \\
Awards Won $=$ High & $0.010(-0.071,0.091)$ \\
Humanities & $0.184^{* * *}(0.142,0.225)$ \\
Medical Sci. & $0.105^{* * *}(0.056,0.153)$ \\
Natural Sci. & $0.070^{* * *}(0.037,0.103)$ \\
Social Sci. & $0.044^{* *}(0.008,0.079)$ \\
Uni. Type $=$ R1 & $0.643(\mathrm{df}=18946)$ \\
Uni. Control $=$ Public & $-0.030^{* * *}(-0.051,-0.010)$ \\
\#Reviews & $-0.084^{* * *}(-0.110,-0.059)$ \\
Constant & $0.006^{* * *}(0.004,0.007)$ \\
\hline Observations & $3.173^{* * *}(3.114,3.231)$ \\
R ${ }^{2}$ & 18,973 \\
Adjusted $\mathrm{R}^{2}$ & 0.514 \\
Residual Std. Error & $\mathrm{p}<0.1 ; * * \mathrm{p}<0.05 ; * * * \mathrm{p}<0.01$ \\
F Statistic &
\end{tabular}

S5 Table. Results of Kendall Rank Tau. Results of non-parametric test of dependence between the RMP2018 overall quality rating of the population, tested against each of the AA2017 research indicators. 


\begin{tabular}{lrrr}
\hline Tested Variable & Z-Value & Estimated Tau & P-Value \\
\hline Article Count & 11.349 & 0.0453 & $<2.2 \mathrm{e}-16$ \\
Award Count & 2.1285 & 0.0093 & 0.0333 \\
Book Count & 10.122 & 0.0444 & $<2.2 \mathrm{e}-16$ \\
Citation Count & 3.2322 & 0.0130 & 0.00123 \\
Proceeding Count & -8.990 & -0.0411 & $<2.2 \mathrm{e}-16$ \\
Grant Count & -5.9901 & -0.0264 & $2.097 \mathrm{e}-09$ \\
\hline
\end{tabular}

S6 Table Results of multiple linear regression model with interactions. For binary variables, "false" is always used as the reference level. For Gender, "female" is used as the reference. For race, "Non-White" is used as the reference. For rank, "Assistant" is used as the reference. For Discipline, "Engineering" is set as the reference. For Uni. Control, "Private" is used as the reference. For Uni. Type, "Not R1" is used as the reference. For all research indicators, "Low" is used as the reference. Estimates are listed first, followed by 95th percentile confidence intervals. Interactions are marked as variables separated by a "*". 831 832 833 834 835 836 837

\begin{tabular}{|c|c|}
\hline & Dependent variable: \\
\hline & overall \\
\hline Is Male & $0.133^{* *}(0.027,0.239)$ \\
\hline Scientific Age & $-0.124^{* * *}(-0.153,-0.095)$ \\
\hline Mentions Accent $=$ True & $-0.161^{* * *}(-0.225,-0.097)$ \\
\hline Has Chili Pepper & $0.424^{* * *}(0.381,0.467)$ \\
\hline Rank $=$ Associate & $0.021(-0.029,0.071)$ \\
\hline Rank $=$ Full & $0.131^{* * *}(0.065,0.197)$ \\
\hline Race unknown & $0.017(-0.035,0.069)$ \\
\hline Race Lilely White & $0.082^{* * *}(0.041,0.123)$ \\
\hline Difficulty & $-0.392^{* * *}(-0.402,-0.382)$ \\
\hline Student Interest & $0.329^{* * *}(0.319,0.339)$ \\
\hline Mentions TA $=$ True & $-0.183^{* * *}(-0.218,-0.148)$ \\
\hline Citedness $=$ Moderate & $-0.023(-0.053,0.007)$ \\
\hline Citedness $=$ High & $-0.034(-0.086,0.018)$ \\
\hline Output $=$ Moderate & $0.035^{*}(-0.0003,0.070)$ \\
\hline Output = High & $0.023(-0.031,0.078)$ \\
\hline Grants Held = Moderate & $-0.0003(-0.025,0.024)$ \\
\hline Grants Held = High & $0.032(-0.023,0.087)$ \\
\hline Awards Won $=$ Moderate & $0.010(-0.011,0.030)$ \\
\hline Awards Won $=$ High & $0.006(-0.076,0.087)$ \\
\hline Humanities & $0.292^{* * *}(0.206,0.378)$ \\
\hline Medical Sci. & $0.182^{* * *}(0.079,0.286)$ \\
\hline Natural Sci. & $0.140^{* * *}(0.054,0.226)$ \\
\hline Social Sci. & $0.093^{* *}(0.011,0.176)$ \\
\hline Uni. Type $=\mathrm{R} 1$ & $-0.031^{* * *}(-0.051,-0.010)$ \\
\hline Uni. Control = Public & $-0.086^{* * *}(-0.111,-0.060)$ \\
\hline \#Reviews & $0.006^{* * *}(0.004,0.007)$ \\
\hline Is Male ${ }^{*}$ Has Chili & $-0.008(-0.059,0.044)$ \\
\hline Is Male * Humanities & $-0.145^{* * *}(-0.237,-0.052)$ \\
\hline Is Male * Medical & $-0.092(-0.210,0.026)$ \\
\hline Is Male * Natural & $-0.082^{*}(-0.175,0.011)$ \\
\hline Is Male * Social & $-0.050(-0.140,0.041)$ \\
\hline Is Male * Scientific Age & $-0.011(-0.043,0.021)$ \\
\hline Is Male * Race unknown & $0.041(-0.020,0.103)$ \\
\hline Is Male * Race Likely White & $0.051^{* *}(0.002,0.100)$ \\
\hline Is Male $*$ Mentions Accent & $-0.014(-0.086,0.059)$ \\
\hline Is Male * Rank Associate & $0.039(-0.023,0.100)$ \\
\hline Is Male * Rank Full & $0.011(-0.066,0.088)$ \\
\hline Constant & $3.140^{* * *}(3.039,3.242)$ \\
\hline Observations & 18,973 \\
\hline $\mathrm{R}^{2}$ & 0.515 \\
\hline Adjusted $\mathrm{R}^{2}$ & 0.514 \\
\hline Residual Std. Error & $0.643(\mathrm{df}=18935)$ \\
\hline F Statistic & $543.120^{* * *}(\mathrm{df}=37 ; 18935)(\mathrm{p}=0.000)$ \\
\hline
\end{tabular}


S7 Table Results of multiple linear regression model using continuous the reference level. For Gender, "female" is used as the reference. For "Rank",

"Assistant" is used as the reference. For Discipline, "Engineering" is set as the reference. For Uni. Control, "Private" is used as the reference. For Uni. Type, "Not R1" is used as the reference. Continuous field-normalized values are used for research performance indicators. Estimates are listed first, followed by 95 th percentile confidence intervals.

\begin{tabular}{lc}
\hline \hline & Dependent variable: \\
\cline { 2 - 2 } & overall \\
\hline Is Male & $0.106^{* * *}(0.083,0.128)$ \\
Scientific Age & $-0.128^{* * *}(-0.143,-0.114)$ \\
Mentions Accent $=$ True & $-0.201^{* * *}(-0.232,-0.170)$ \\
Has Chili Pepper & $0.405^{* * *}(0.379,0.431)$ \\
Rank $=$ Associate & $0.016(-0.013,0.045)$ \\
Rank = Full & $0.108^{* * *}(0.071,0.145)$ \\
Difficulty & $-0.405^{* * *}(-0.416,-0.394)$ \\
Student Interest & $0.365^{* * *}(0.354,0.376)$ \\
Mentions TA $=$ True & $-0.181^{* * *}(-0.217,-0.145)$ \\
Citations & $-0.002(-0.007,0.002)$ \\
Publications & $0.006(-0.004,0.017)$ \\
Awards & $0.008^{* *}(0.001,0.014)$ \\
Grants & $0.001(-0.003,0.005)$ \\
Humanities & $0.213^{* * *}(0.176,0.250)$ \\
Medical Sci. & $0.116^{* * *}(0.064,0.167)$ \\
Natural Sci. & $0.079^{* * *}(0.044,0.113)$ \\
Social Sci. & $0.065^{* * *}(0.029,0.101)$ \\
Uni. Type $=$ R1 & $-0.031^{* * *}(-0.052,-0.010)$ \\
Uni. Control $=$ Public & $-0.079^{* * *}(-0.106,-0.052)$ \\
\#Reviews & $0.006^{* * *}(0.004,0.008)$ \\
Constant & $3.279^{* * *}(3.227,3.331)$ \\
\hline Observations & 17,600 \\
$\mathrm{R}^{2}$ & 0.513 \\
Adjusted R ${ }^{2}$ & 0.512 \\
Residual Std. Error & $0.643(\mathrm{df}=17579)$ \\
F Statistic & ${ }^{*} \mathrm{p}<0.1 ;{ }^{* *} \mathrm{p}<0.05 ;{ }^{* * *} \mathrm{p}<0.01$ \\
\hline \hline Note: & $925.473^{* * *}(\mathrm{df}=20 ; 17579)(\mathrm{p}=0.000)$ \\
&
\end{tabular}


S8 Table. Little evidence of multicollinearity in discrete regression model. Generalized and adjusted variance inflation factor scores for the regression model of overall teaching quality with discrete research indicators.

\begin{tabular}{cccc}
\hline \hline & GVIF & Df & GVIF $^{\wedge}(1 /(2 *$ Df $))$ \\
\hline Gender & 1.115 & 1 & 1.056 \\
Scientific Age & 2.312 & 1 & 1.521 \\
Mentions Accent & 1.101 & 1 & 1.049 \\
Has Chili Pepper & 1.178 & 1 & 1.085 \\
Rank & 2.146 & 2 & 1.210 \\
Race & 1.067 & 2 & 1.016 \\
Difficulty & 1.121 & 1 & 1.059 \\
Interest & 1.121 & 1 & 1.059 \\
Mentions TA & 1.097 & 1 & 1.047 \\
Citedness & 2.766 & 2 & 1.290 \\
Output & 1.988 & 2 & 1.187 \\
Grants & 1.582 & 2 & 1.121 \\
Awards Won & 1.190 & 2 & 1.044 \\
Discipline & 2.251 & 4 & 1.107 \\
Uni. Type & 1.054 & 1 & 1.027 \\
Uni. Control & 1.019 & 1 & 1.010 \\
Review Count & 1.125 & 1 & 1.061 \\
\hline
\end{tabular}


S9 Table. Little evidence of multicollinearity in continuous regression model. Generalized and adjusted variance inflation factor scores for the regression model of overall teaching quality with continuous research indicators.

\begin{tabular}{cccc}
\hline \hline & GVIF & Df & GVIF $^{\wedge}(1 /(2 *$ Df $))$ \\
\hline Gender & 1.115 & 1 & 1.056 \\
Scientific Age & 2.073 & 1 & 1.440 \\
Mentions Accent & 1.061 & 1 & 1.030 \\
Has Chili Papper & 1.175 & 1 & 1.084 \\
Rank & 2.029 & 2 & 1.193 \\
Difficulty & 1.119 & 1 & 1.058 \\
Interest & 1.120 & 1 & 1.058 \\
Mentions TA & 1.096 & 1 & 1.047 \\
Norm. Citations & 1.423 & 1 & 1.193 \\
Norm. Publications & 1.525 & 1 & 1.235 \\
Norm. Awards & 1.123 & 1 & 1.060 \\
Norm. Grants & 1.063 & 1 & 1.031 \\
Discipline & 1.200 & 4 & 1.023 \\
Uni. Type & 1.034 & 1 & 1.017 \\
Uni. Control & 1.019 & 1 & 1.010 \\
Review Count & 1.121 & 1 & 1.059 \\
\hline
\end{tabular}


S10 Table Little difference between population of matched and unmatched Academic Analytics faculty. Shown are characteristics of the faculty in the matched dataset and of the tenure and tenure-track faculty of the unmatched Academic Analytics dataset.

\begin{tabular}{|c|c|c|c|}
\hline Variable & Measure & Matched & Unmatched \\
\hline \multirow{2}{*}{ Gender } & $\%$ Male & 71.5 & 64.2 \\
\hline & $\%$ Female & 28.5 & 35.8 \\
\hline \multirow{3}{*}{ Inferred Race } & $\%$ White & 54.4 & 56.9 \\
\hline & $\%$ Non-White & 26.9 & 25.5 \\
\hline & \% Unknown & 18.8 & 17.5 \\
\hline \multirow{3}{*}{ Professional Rank } & \%Assistant & 17.8 & 23.4 \\
\hline & \%Associate & 35.9 & 27.3 \\
\hline & $\%$ Full & 46.4 & 49.3 \\
\hline \multirow{3}{*}{ Scientific Age } & 1st Quartile & 11 & 12 \\
\hline & Median & 20 & 21 \\
\hline & 3rd Quartile & 30 & 21 \\
\hline \multirow{2}{*}{ University Type } & $\% \mathrm{R} 1$ & 69.9 & 39.7 \\
\hline & $\%$ Not R1 & 30.1 & 30.3 \\
\hline \multirow{2}{*}{ University Control } & \%Private & 15.7 & 28.4 \\
\hline & $\%$ Public & 84.3 & 71.6 \\
\hline \multirow{5}{*}{ Discipline } & $\%$ Engineering & 10.7 & 13.2 \\
\hline & $\%$ Social Science & 21.9 & 25 \\
\hline & $\%$ Medical Science & 5.5 & 26.7 \\
\hline & $\%$ Natural Science & 33.6 & 22.9 \\
\hline & $\%$ Humanities & 21.3 & 12.3 \\
\hline \multirow{3}{*}{ Publications } & $\%$ No Publications & 19.6 & 14.2 \\
\hline & \% Moderate Publications & 73.1 & 76.8 \\
\hline & $\%$ High Publications & 7.2 & 9.5 \\
\hline \multirow{3}{*}{ Citations } & $\%$ No Citations & 28 & 19 \\
\hline & $\%$ Moderate Citations & 66.2 & 72.7 \\
\hline & $\%$ High Citations & 5.8 & 8.4 \\
\hline \multirow{3}{*}{ Grants } & $\%$ No Grants & 65.8 & 60.6 \\
\hline & \% Moderate Grants & 31.1 & 35.4 \\
\hline & \% High Grants & 3.1 & 4 \\
\hline \multirow{3}{*}{ Awards } & $\%$ No Awards & 64.6 & 67.5 \\
\hline & $\%$ Moderate Awards & 33.9 & 28.9 \\
\hline & $\%$ High Awards & 1.5 & 3.6 \\
\hline
\end{tabular}




\begin{tabular}{lrrrrrr}
\hline Discipline & Articles & Proceedings & Books & Awards & Citations & Grants \\
\hline Engineering & 12.034 & 5.921 & 0.348 & 0.805 & 189.504 & 1.566 \\
Humanities & 1.451 & 0.044 & 1.721 & 0.846 & 3.428 & 0.114 \\
Medical Sciences & 11.917 & 0.398 & 0.304 & 0.616 & 207.930 & 1.345 \\
Natural Sciences & 15.319 & 1.931 & 0.340 & 0.755 & 474.638 & 1.452 \\
Social Sciences & 5.854 & 0.182 & 0.990 & 0.489 & 62.174 & 0.357 \\
\hline
\end{tabular}

\section{Acknowledgments}

This work is funded by the National Science Foundation award \#1561299 (EAGER: Illuminating the role of science funding on disparities in science). We would like to thank Academic Analytics for providing access to their data. We thank our anonymous reviewers whose comments contributed to this manuscript.

\section{References}

1. Bogt HJt, Scapens RW. Performance Management in Universities: Effects of the Transition to More Quantitative Measurement Systems. European Accounting Review. 2012;21(3):451-497. doi:10.1080/09638180.2012.668323.

2. Boyer EL. Scholarship Reconsidered: Priorities of the Professoriate. 1st ed. Princeton, NJ: Jossey-Bass; 1997.

3. Boring A, Ottoboni K, Stark P. Student Evaluations of Teaching (Mostly) Do Not Measure Teaching Effectiveness. ScienceOpen Research. 2016;doi:10.14293/S2199-1006.1.SOR-EDU.AETBZC.v1.

4. Miles P, House D. The Tail Wagging the Dog; An Overdue Examination of Student Teaching Evaluations. International Journal of Higher Education. 2015;4(2):116-126.

5. Mengel F, Sauermann J, Zölitz U. Gender bias in teaching evaluations. Journal of the European Economic Association. 2017;

6. Reid LD. The role of perceived race and gender in the evaluation of college teaching on RateMyProfessors.Com. Journal of Diversity in Higher Education. 2010;3(3):137-152. doi:10.1037/a0019865.

7. Wilson JH, Beyer D, Monteiro H. Professor Age Affects Student Ratings: Halo Effect for Younger Teachers. College Teaching. 2014;62(1):20-24. doi:10.1080/87567555.2013.825574.

8. MacNell L, Driscoll A, Hunt AN. What's in a Name: Exposing Gender Bias in Student Ratings of Teaching. Innov High Educ. 2015;40(4):291-303. doi:10.1007/s10755-014-9313-4.

9. Smith BP, Hawkins B. Examining Student Evaluations of Black College Faculty: Does Race Matter? The Journal of Negro Education. 2011;80(2):149-162. 
10. Sohr-Preston SL, Boswell SS, McCaleb K, Robertson D. Professor Gender, Age, and "Hotness" in Influencing College Students' Generation and Interpretation of Professor Ratings. Higher Learning Research Communications. 2016;6(3).

11. Stonebraker RJ, Stone GS. Too Old to Teach? The Effect of Age on College and University Professors. Res High Educ. 2015;56(8):793-812. doi:10.1007/s11162-015-9374-y.

12. Joye SW, Wilson JH. Professor Age and Gender Affect Student Perceptions and Grades. Journal of the Scholarship of Teaching and Learning. 2015;15(4):126-138.

13. Uttl B, Smibert D. Student evaluations of teaching: teaching quantitative courses can be hazardous to one's career. PeerJ. 2017;5:e3299. doi:10.7717/peerj.3299.

14. Boysen GA, Kelly TJ, Raesly HN, Casner RW. The (mis)interpretation of teaching evaluations by college faculty and administrators. Assessment \& Evaluation in Higher Education. 2014;39(6):641-656. doi:10.1080/02602938.2013.860950.

15. Adams MJD, Umbach PD. Nonresponse and Online Student Evaluations of Teaching: Understanding the Influence of Salience, Fatigue, and Academic Environments. Research in Higher Education. 2012;53(5):576-591. doi:10.1007/s11162-011-9240-5.

16. Gruber T, Lowrie A, Brodowsky GH, Reppel AE, Voss R, Chowdhury IN. Investigating the Influence of Professor Characteristics on Student Satisfaction and Dissatisfaction: A Comparative Study. Journal of Marketing Education. 2012;34(2):165-178. doi:10.1177/0273475312450385.

17. Cramer KM, Alexitch LR. Student Evaluations of College Professors: Identifying Sources of Bias. Canadian Journal of Higher Education. 2000;30(2):143-164.

18. Sheehan DS. On the Invalidity of Student Ratings for Administrative Personnel Decisions. The Journal of Higher Education. 1975;46(6):687-700. doi: $10.2307 / 1979062$.

19. Bunge N. Students Evaluating Teachers Doesn't Just Hurt Teachers. It Hurts Students. The Chronicle of Higher Education. 2018;

20. Falkoff M. Why We Must Stop Relying on Student Ratings of Teaching. The Chronicle of Higher Education. 2018;.

21. Flaherty C. Most institutions say they value teaching but how they assess it tells a different story. Inside Higher Ed. 2018;.

22. Zabaleta F. The use and misuse of student evaluations of teaching. Teaching in Higher Education. 2007;12(1):55-76. doi:10.1080/13562510601102131.

23. Habermas J, Blazek JR. The Idea of the University: Learning Processes. New German Critique. 1987;(41):3-22. doi:10.2307/488273.

24. Neumann R. Perceptions of the Teaching-Research Nexus: A Framework for Analysis. Higher Education. 1992;23(2):159-171. doi:10.2307/3447303.

25. Neumann R. The Teaching-Research Nexus: Applying a Framework to University Students' Learning Experiences. European Journal of Education. 1994;29(3):323-338. doi:10.2307/1503744. 
26. Turner N, Wuetherick B, Healey M. International perspectives on student awareness, experiences and perceptions of research: implications for academic developers in implementing research based teaching and learning. International Journal for Academic Development. 2008;13(3):199-211. doi:10.1080/13601440802242333.

27. Brennan L, Cusack T, Delahunt E, Kuznesof S, Donnelly S. Academics' conceptualisations of the research-teaching nexus in a research-intensive Irish university: A dynamic framework for growth \& development. Learning and Instruction. 2019;60:301-309. doi:10.1016/j.learninstruc.2017.10.005.

28. Galbraith CS, Merrill GB. Faculty Research Productivity and Standardized Student Learning Outcomes in a University Teaching Environment: A Bayesian Analysis of Relationships. Studies in Higher Education. 2012;37(4):469-480. doi:10.1080/03075079.2010.523782.

29. Taylor J. The teaching:research nexus : a model for institutional management. Higher Education. 2007;54(6):867-884. doi:10.1007/s10734-006-9029-1.

30. Carter RE. Faculty Scholarship Has a Profound Positive Association With Student Evaluations of Teaching - Except When It Doesn't. Journal of Marketing Education. 2016;38(1):18-36. doi:10.1177/0273475315604671.

31. Courant PN, Turner S. Faculty Deployment in Research Universities. National Bureau of Economic Research; 2017. 23025. Available from: http://www.nber.org/papers/w23025

32. Coate K, Barnett R, Williams G. Relationships Between Teaching and Research in Higher Education in England. Higher Education Quarterly. 2001;55(2):158-174. doi:10.1111/1468-2273.00180.

33. Gomez-Mejia LR, Balkin DB. Determinants of Faculty Pay: An Agency Theory Perspective. The Academy of Management Journal. 1992;35(5):921-955. doi:10.2307/256535.

34. Hattie J, Marsh HW. The Relationship Between Research and Teaching: A Meta-Analysis. Review of Educational Research. 1996;66(4):507-542. doi:10.3102/00346543066004507.

35. Miller JD. How To Fight RateMyProfessors.com | Inside Higher Ed; 2006. Available from: https://www.insidehighered.com/views/2006/01/31/ how-fight-ratemyprofessorscom

36. Davison E, Price J. How do we rate? An evaluation of online student evaluations. Assessment \& Evaluation in Higher Education. 2009;34(1):51-65. doi:10.1080/02602930801895695.

37. Gregory KM. How Undergraduates Perceive Their Professors: A Corpus Analysis of Rate My Professor. Journal of Educational Technology Systems. 2011;40(2):169-193. doi:10.2190/ET.40.2.g.

38. Kindred J, Mohammed SN. "He Will Crush You Like an Academic Ninja!" Exploring Teacher Ratings on Ratemyprofessors.com. Journal of Computer-Mediated Communication. 2005;10(3):00-00. doi:10.1111/j.1083-6101.2005.tb00257.x.

39. Coladarci T, Kornfield I. RateMyProfessors. com versus formal in-class student evaluations of teaching. Practical Assessment \& Research Evaluation. 2007;12(6). 
40. Silva KM, Silva FJ, Quinn MA, Draper JN, Cover KR, Munoff AA. Rate My Professor: Online Evaluations of Psychology Instructors. Teaching of Psychology. 2008;35(2):71-80. doi:10.1080/00986280801978434.

41. About RateMyProfessors.com;. Available from: http://www.ratemyprofessors.com/About.jsp.

42. Leydesdorff L, Shin JC. How to Evaluate Universities in Terms of Their Relative Citation Impacts: Fractional Counting of Citations and the Normalization of Differences Among Disciplines. J Am Soc Inf Sci Technol. 2011;62(6):1146-1155. doi:10.1002/asi.21511.

43. Winkler WE. The State of Record Linkage and Current Research Problems. Washington, DC: Statistical Research Division, U.S. Bureau of the Census; 1999. Available from: https://www.census.gov/srd/papers/pdf/rr99-04.pdf.

44. Winkler WE. Overview of Record Linkage and Current Research Directions. Washington, DC: Statistical Research Division, U.S. Bureau of the Census; 2006. \#2006-2. Available from: https://www.census.gov/srd/papers/pdf/rrs2006-02.pdf

45. Jaro MA. Advances in Record-Linkage Methodology as Applied to Matching the 1985 Census of Tampa, Florida. Journal of the American Statistical Association. 1989;84(406):414-420. doi:10.1080/01621459.1989.10478785.

46. Rosen AS. Correlations, trends and potential biases among publicly accessible web-based student evaluations of teaching: a large-scale study of RateMyProfessors.com data. Assessment \& Evaluation in Higher Education. 2018;43(1):31-44. doi:10.1080/02602938.2016.1276155.

47. DeMeis DK, Turner RR. Effects of students' race, physical attractiveness, and dialect on teachers' evaluations. Contemporary Educational Psychology. 1978;3(1):77-86. doi:10.1016/0361-476X(78)90012-7.

48. Tsou A, Bowman TD, Sugimoto T, Lariviere V, Sugimoto CR. Self-presentation in scholarly profiles: Characteristics of images and perceptions of professionalism and attractiveness on academic social networking sites. First Monday. 2016;21(4). doi:10.5210/fm.v21i4.6381.

49. Feeley T. Evidence of Halo Effects in Student Evaluations of Communication Instruction. Communication Education. 2002;51(3):225-236. doi:10.1080/03634520216519.

50. Lewis MB. Who is the fairest of them all? Race, attractiveness and skin color sexual dimorphism. Personality and Individual Differences. 2011;50(2):159-162. doi:10.1016/j.paid.2010.09.018.

51. Schmit B. Gendered Language in Teaching Evaluations; 2015. Available from: http://benschmidt.org/profGender.

52. Ch $\tilde{A}_{j \mathrm{vez}} \mathrm{K}$, Mitchell KMW. Exploring Bias in Student Evaluations: Gender, Race, and Ethnicity. PS: Political Science \& Politics. 2019; p. 1-5. doi:10.1017/S1049096519001744.

53. Kavas A, Kavas A. An Exploratory Study of Undergraduate College Students' Perceptions and Attitudes toward Foreign Accented Faculty. College Student Journal. 2008;42(3):879-890. 
54. Gill MM. Accent and stereotypes: Their effect on perceptions of teachers and lecture comprehension. Journal of Applied Communication Research. 1994;22(4):348-361. doi:10.1080/00909889409365409.

55. Subtirelu NC. "She does have an accent but...": Race and language ideology in students' evaluations of mathematics instructors on RateMyProfessors.com. Language in Society. 2015;44(1):35-62. doi:10.1017/S0047404514000736.

56. Figlio DN, Schapiro MO, Soter KB. Are Tenure Track Professors Better Teachers? National Bureau of Economic Research; 2013. 19406. Available from: http://www.nber.org/papers/w19406

57. Centra JA. Will Teachers Receive Higher Student Evaluations by Giving Higher Grades and Less Course Work? Research in Higher Education. 2003;44(5):495-518. doi:10.1023/A:1025492407752.

58. Otto J, Jr DAS, Ross DN. Does ratemyprofessor.com really rate my professor? Assessment \& Evaluation in Higher Education. 2008;33(4):355-368. doi:10.1080/02602930701293405.

59. Clayson DE, Haley DA. Student Evaluations in Marketing: What is Actually being Measured? Journal of Marketing Education. 1990;12(3):9-17. doi:10.1177/027347539001200302.

60. Marsh HW. The Influence of Student, Course, and Instructor Characteristics in Evaluations of University Teaching. American Educational Research Journal. 1980;17(2):219-237. doi:10.3102/00028312017002219.

61. Darby JA. The effects of the elective or required status of courses on student evaluations. Journal of Vocational Education \& Training. 2006;58(1):19-29. doi:10.1080/13636820500507708.

62. Feldman KA. Class size and college students' evaluations of teachers and courses: A closer look. Research in Higher Education. 1984;21(1):45-116. doi:10.1007/BF00975035.

63. Mateo MA, Fernandez J. Incidence of Class Size on the Evaluation of University Teaching Quality. Educational and Psychological Measurement. 1996;56(5):771-778. doi:10.1177/0013164496056005004.

64. Rojstaczer S, Healy C. Where A Is Ordinary: The Evolution of American College and University Grading, 1940-2009. Teachers College Record. 2012;114(7):1-23.

65. Ewing AM. Estimating the impact of relative expected grade on student evaluations of teachers. Economics of Education Review. 2012;31(1):141-154. doi:10.1016/j.econedurev.2011.10.002.

66. Hattie J, Marsh H. One Journey to Unravel the Relationship between Research and Teaching - Semantic Scholar. Hampshire, UK; 2004.Available from: /paper/ One-Journey-to-Unravel-the-Relationship-between-Re-Hattie-Marsh/ 62b93dcdcfcefaa6bb905c536609516f498ce3c1.

67. Figlio D, Schapiro MO. Are great teachers poor scholars? Brookings Institute; 2017. Available from: https: //www.brookings.edu/research/are-great-teachers-poor-scholars/. 
68. Euwals R, Ward ME. What matters most: teaching or research? Empirical evidence on the remuneration of British academics. Applied Economics. 2005;37(14):1655-1672. doi:10.1080/00036840500181620.

69. Gottlieb EE, Keith B. The academic research-teaching nexus in eight advanced-industrialized countries. Higher Education. 1997;34(3):397-419. doi:10.1023/A:1003028023964.

70. Arnold IJM. Course Level and the Relationship between Research Productivity and Teaching Effectiveness. The Journal of Economic Education. 2008;39(4):307-321. doi:10.3200/JECE.39.4.307-321.

71. Stack S. Research Productivity and Student Evaluation of Teaching in Social Science Classes: A Research Note. Research in Higher Education. 2003;44(5):539-556. doi:10.1023/A:1025439224590.

72. Brew A, Boud D. Teaching and research: Establishing the vital link with learning. High Educ. 1995;29(3):261-273. doi:10.1007/BF01384493.

73. Hornstein HA. Student evaluations of teaching are an inadequate assessment tool for evaluating faculty performance. Cogent Education. 2017;4(1):1304016. doi:10.1080/2331186X.2017.1304016.

74. Smeby JC. Knowledge Production and Knowledge Transmission. The interaction between research and teaching at universities. Teaching in Higher Education. 1998;3(1):5-20. doi:10.1080/1356215980030101.

75. Bak HJ, Kim DH. Too much Emphasis on Research? An Empirical Examination of the Relationship Between Research and Teaching in Multitasking Environments. Res High Educ. 2015;56(8):843-860. doi:10.1007/s11162-015-9372-0.

76. The Annual Report on the Economic Status of the Profession, 2018 - 19. Washington D.C., U.S.A.: American Association of University Professors; 2019. Available from: https://www . aaup.org/sites/default/files/2018-19_ARES_Final_0.pdf

77. Pasma C, Shaker E. Contract U: Contract faculty appointments at Canadian universities. Ottowa, Canada: Canadian Centre for Policy Alternatives; 2018.

78. Friedman J. 10 Universities Where TAs Teach the Most Classes. US News \& World Report. 2017;

79. Murray DS. The precarious new faculty majority: communication and instruction research and contingent labor in higher education. Communication Education. 2019;68(2):235-245. doi:10.1080/03634523.2019.1568512.

80. Fong C, Dillard J, Hatcher M. Teaching Self-Efficacy of Graduate Student Instructors: Exploring Faculty Motivation, Perceptions of Autonomy Support, and Undergraduate Student Engagement. International Journal of Educational Research. 2019;98. doi:10.1016/j.ijer.2019.08.018.

81. Patridge EV, Barthelemy RS, Rankin SR. FACTORS IMPACTING THE ACADEMIC CLIMATE FOR LGBQ STEM FACULTY. Journal of Women and Minorities in Science and Engineering. 2014;20(1). doi:10.1615/JWomenMinorScienEng.2014007429. 
82. Nielsen EJ, Alderson KG. Lesbian and Queer Women Professors Disclosing in the Classroom: An Act of Authenticity. The Counseling Psychologist.

2014;doi:10.1177/0011000014554839.

83. Dilley P. LGBTQ Research in Higher Education: A Review of Journal Articles, 2000 - 2003. Journal of Gay \& Lesbian Issues in Education. 2004;2(2):105-115. doi:10.1300/J367v02n02_12.

84. Flaherty C. Rutgers Graduate School faculty takes a stand against Academic Analytics; 2016. Available from: https : //www . insidehighered.com/news/2016/05/11/ rutgers-graduate-school-faculty-takes-stand-against-academic-analytics

85. van Eck NJ, Waltman L, Larivière V, Sugimoto CR. Crossref as a new source of citation data: A comparison with Web of Science and Scopus; 2018. Available from: https://www.cwts.nl:443/blog?article=n-r2s234\&title= crossref-as-a-new-source-of-citation-data-a-comparison-with-web-of-scienc

86. Mongeon P, Paul-Hus A. The Journal Coverage of Web of Science and Scopus: a Comparative Analysis. Scientometrics. 2016;106(1):213-228. doi:10.1007/s11192-015-1765-5.

87. Sonntag ME, Bassett JF, Snyder T. An Empirical Test of the Validity of Student Evaluations of Teaching Made on RateMyProfessors.com. Assessment \& Evaluation in Higher Education. 2009;34(5):499-504.

88. Ioannidis JPA, Boyack K, Wouters PF. Citation Metrics: A Primer on How (Not) to Normalize. PLoS Biology. 2016;14(9). doi:10.1371/journal.pbio.1002542.

89. Clayson DE. What does ratemyprofessors.com actually rate? Assessment \& Evaluation in Higher Education. 2014;39(6):678-698. doi:10.1080/02602938.2013.861384.

90. Larivière V, Ni C, Gingras Y, Cronin B, Sugimoto CR. Bibliometrics: Global gender disparities in science. Nature News. 2013;504(7479):211. doi:10.1038/504211a.

91. Boyle PJ, Smith LK, Cooper NJ, Williams KS, O'Connor H. Gender balance: Women are funded more fairly in social science. Nature News. 2015;525(7568):181. doi:10.1038/525181a.

92. Leslie SJ, Cimpian A, Meyer M, Freeland E. Expectations of brilliance underlie gender distributions across academic disciplines. Science (New York, NY). 2015;347(6219):262-265. doi:10.1126/science.1261375. 